\title{
Review Article \\ Potential Role of Epigenetic Mechanism in Manganese Induced Neurotoxicity
}

\author{
Prashant Tarale, ${ }^{1}$ Tapan Chakrabarti, ${ }^{2}$ Saravanadevi Sivanesan, ${ }^{1}$ \\ Pravin Naoghare, ${ }^{1}$ Amit Bafana, ${ }^{1}$ and Kannan Krishnamurthi ${ }^{1}$ \\ ${ }^{1}$ Environmental Health Division, CSIR-National Environmental Engineering Research Institute, Nagpur 440020, India \\ ${ }^{2}$ Visvesvaraya National Institute of Technology (VNIT), Nagpur 440010, India
}

Correspondence should be addressed to Saravanadevi Sivanesan; ss_devi@neeri.res.in

Received 17 February 2016; Accepted 8 May 2016

Academic Editor: Andrei Surguchov

Copyright (C) 2016 Prashant Tarale et al. This is an open access article distributed under the Creative Commons Attribution License, which permits unrestricted use, distribution, and reproduction in any medium, provided the original work is properly cited.

Manganese is a vital nutrient and is maintained at an optimal level $(2.5-5 \mathrm{mg} /$ day $)$ in human body. Chronic exposure to manganese is associated with neurotoxicity and correlated with the development of various neurological disorders such as Parkinson's disease. Oxidative stress mediated apoptotic cell death has been well established mechanism in manganese induced toxicity. Oxidative stress has a potential to alter the epigenetic mechanism of gene regulation. Epigenetic insight of manganese neurotoxicity in context of its correlation with the development of parkinsonism is poorly understood. Parkinson's disease is characterized by the $\alpha$-synuclein aggregation in the form of Lewy bodies in neuronal cells. Recent findings illustrate that manganese can cause overexpression of $\alpha$-synuclein. $\alpha$-Synuclein acts epigenetically via interaction with histone proteins in regulating apoptosis. $\alpha$-Synuclein also causes global DNA hypomethylation through sequestration of DNA methyltransferase in cytoplasm. An individual genetic difference may also have an influence on epigenetic susceptibility to manganese neurotoxicity and the development of Parkinson's disease. This review presents the current state of findings in relation to role of epigenetic mechanism in manganese induced neurotoxicity, with a special emphasis on the development of Parkinson's disease.

\section{Introduction}

Manganese $(\mathrm{Mn})$ is an essential trace element maintained at an optimal level in human body for proper functioning of brain. Manganese also plays significant role in carbohydrate, lipid, and protein metabolism and acts as a cofactor for various antioxidant enzymes like superoxide dismutase, glutamine synthetase, and so forth [1]. Chronic exposure to manganese is known to induce neurotoxicity [2]. Most of the epidemiological studies on exposure to manganese pertain to its effect on occupational workers. High environment level of manganese may be a potential risk factor in causing disorder associated with developing nervous system as well as for adult brain $[3,4]$. Welders and miners are the diverse occupational population who are exposed to manganese. Manganese, through inhalation, enters the body circulation and affects the central nervous system [5]. The neurological disorders similar to schizophrenia and Parkinson's disease (PD) have been observed to be due to excessive manganese intake from both environment and occupational settings characterized by dopaminergic cell death $[6,7]$. Occupational exposure of manganese at an elevated level may cause manganism with neurological symptoms resembling idiopathic Parkinson's disease (IPD) [8]. Settivari's study showed the probable genetic linkage between manganism and idiopathic Parkinson's disease (IPD) [8]. This suggests the common molecular modalities involved in pathophysiology of both disorders. However the identification of key molecular determinants largely remains elusive. This prolonged exposure has been associated with increased risk for PD $[9,10]$. Initiation of oxidative stress resulting from discrepancy between ROS and antioxidant generation is considered to be the probable mechanism of neurotoxicity as manganese can initiate apoptosis and/or necrotic cell death in neuronal or glial cells [1113].

Dynamic chromatin remodeling governs the accessibility of transcription factors to promoters regions of genes, thereby regulating gene expression [14]. Epigenetic mechanisms such 
as DNA methylation, histone modification, and microRNAs participate in regulating the gene expression. A growing number of evidences suggest that exposure to environmental toxicants may induce alterations in gene expression through epigenetic mechanisms that can be linked to disease susceptibility and development. Epigenetic deregulation may lead to the development of neurological disorders like Parkinson's disease, Huntington's disease, and mood disorders (depression and anxiety) [15]. Millions of people worldwide are affected by the most common movement disorder known as Parkinson's disease (PD). Apart from mutation in genome, various environmental and occupational factors such as pesticides like paraquat and metals such as manganese have been considered as risk factor for the development of Parkinson's disease [16]. Parkinson's disease is characterized by the presence of $\alpha$-synuclein proteinaceous inclusions, known as Lewy bodies (LBs) and Lewy neurites (LNs) in the dopaminergic neurons of brain. $\alpha$-Synuclein aggregation in neuronal cells in form of Lewy bodies is a pathological hallmark of Parkinson's disease. Manganese has been found to accelerate the $\alpha$-synuclein aggregation in neuronal cell line by inducing the overexpression of $\alpha$-synuclein [17]. The significance of elevated $\alpha$-synuclein expression can be understood by the fact that $50 \%$ increase in $\alpha$-synuclein expression has been hypothesized to cause Parkinson's disease [18]. ROS have the potential to influence epigenetic processes through oxidative stress mechanism [19].

The review is an effort to generate the working hypothesis based on the present knowledge of mechanism underlying the manganese exposure, parkinsonism, and epigenetic modifications over genetic susceptibility. There are many assumptions suggested, lacking epigenetic studies on manganese exposure. It is also an attempt to link the possible role of epigenetic mechanism in implication of Parkinson's disease induced by manganese. The hypothesis indicated in this review may be relevant and needed consideration in future studies.

\section{Manganese in Environment and Its Route of Exposure}

Even though manganese is required in trace amount, exposure from both environmental and occupational settings has been reported to be toxic for brain and central nervous system (CNS). During each life stage the increased exposure to manganese may occur with different absorption routes. Hence lifetime exposure to manganese is important in considering its toxicological aspect [20]. Table 1 depicts the major sources and route of manganese exposure. Relative potential for exposure depends on the sources of exposure. For example, intake due to inhalation of ambient air has higher risk potential compared to that of the ingestion of manganese from diet, drinking water, and so forth.

Manganese is common constituent of ground water. Elevated level of manganese may exist because of certain bedrock formation (geogenic) or anthropogenic activities [21]. Common population could be exposed to high level of manganese through consumption of well/drinking water or inhalation of atmospheric air with manganese released as a combustion product of methylcyclopentadienyl manganese tricarbonyl (MMT) (a petrol antiknock additive) [21-23]. Exposure to manganese through contaminated drinking water that exceeds the WHO regulatory standards $(400 \mu \mathrm{g} / \mathrm{L})$ has been associated with adverse neurological problems [24, 25]. Manganese exposure through water rather than diet has been associated with significant deposition of manganese in hair samples of children [26]. Manganese has been found in breast milk of population residing near to industrial steel plant [27]. As a nutritional supplement, manganese is added to a variety of foods such as soy containing infant formulas. The highest concentration of manganese has been reported in herbal food including grain, rice, nuts, and tea [2830]. Manganese-containing pesticides maneb and paraquat have been used to treat various plant pathologies [31]. An epidemiological observation has reported an increased risk of developing Parkinson's disease in rural area population exposed to these pesticides [31-33]. Elevated intake above a recommended level may be a concern in dietary foods for general population. Neurotoxicity of manganese varies with its route of exposure. Toxicity of manganese is least among all other toxic trace metals when uptake is via ingestion compared to its exposure through inhalation (Table 1). Inhaled manganese provides a direct path to brain tissue through olfactory neural pathway (nasal airways) while lung uptake has long residence time with continuous source of exposure. The intake of manganese via inhalation rather than ingestion is a major concern as it is evident that inhaled manganese enters the body circulation and can be directly transported to the central nervous system [34]. Manganese is found at higher level in ambient air near industries engaged with processing or use of manganese. To increase the strength and stiffness, manganese is used in the steelmaking industries. The miners and workers of ferroalloy, smelting, and metallurgy industries along with battery and car machine manufactures are the heterogeneous population who are occupationally exposed to respirable metal dust particles [35-37]. The Unified Parkinson's Disease Rating Motor Scale 3 (UPDRS3) was used for accessing the risk of parkinsonism in welding fumes exposed workers. The results of the study depict significant difference in the UPDRS3 scale of welding exposed and nonwelder reference subjects [38]. This signifies the association between welding fume exposure and parkinsonism. Positron emission tomography and radiotracer FDOPA based investigation of welding workers with mild parkinsonism sign have shown the evidence of dopaminergic dysfunction in the caudate nucleus [39]. This strengthens the evidence for neurotoxic effects of welding fumes.

Epidemiological observation and studies show that manganism and parkinsonism are the two manifestations of manganese exposure. These neurodegenerative manifestations may stand at two extreme conditions depending on the intensity, duration, and route of exposure [40]. Manganism is the result of high acute exposure whereas parkinsonism happens due to low chronic exposure. According to the WHO, manganism can occur when the airborne concentration of manganese in inhalable particles is above $1 \mathrm{mg} / \mathrm{m}^{3}$ while parkinsonism may result from lifetime exposure to much lower concentration of around $100 \mathrm{ng} / \mathrm{m}^{3}$ of manganese 
TABLE 1: The table shows the major sources and routes of manganese exposure along with their relative potential for exposure to population.

\begin{tabular}{|c|c|c|c|}
\hline Route of exposure & Source of exposure & Basis for exposure & Relative potential for exposure \\
\hline \multirow{3}{*}{ Ingestion } & Diet & $\begin{array}{l}\text { Manganese in breast milk, infant formula, } \\
\text { and leafy vegetables, fruit, and fruit juices }\end{array}$ & $\begin{array}{c}\text { Relatively lower for general } \\
\text { population but higher prenatal } \\
\text { and infant exposure }\end{array}$ \\
\hline & $\begin{array}{l}\text { Ground water } \\
\text { Drinking water } \\
\text { Surface water }\end{array}$ & $\begin{array}{l}\text { As a natural constituent of water but } \\
\text { elevated level may present at some water } \\
\text { source because of pollution sources or } \\
\text { bedrock formation }\end{array}$ & Lower \\
\hline & Soil & $\begin{array}{l}\text { Manganese may present in soil but not a } \\
\text { major contributor to exposure }\end{array}$ & Lower \\
\hline \multirow[t]{2}{*}{ Inhalation } & Ambient air & $\begin{array}{l}\text { Higher air concentration nearby } \\
\text { industries (mining operations, metal } \\
\text { processing plants, etc.) (MMT as additive } \\
\text { in gasoline) is cause of concern for } \\
\text { residential population }\end{array}$ & Higher \\
\hline & Indoor air & $\begin{array}{l}\text { Significantly lower but associated with } \\
\text { Mn in outdoor dust and the distance } \\
\text { from industrial point sources }\end{array}$ & $\begin{array}{l}\text { Relatively lower but implication } \\
\text { for childhood exposure }\end{array}$ \\
\hline
\end{tabular}

in respirable dust particles [35, 41-43]. The delayed and long term toxicity may result due to cumulative exposure to manganese along with other known neurotoxicants such as pesticide and lead. Brain may be unable to compensate the exposure to multiple neurotoxicants leading to persistent and cumulative damage [44]. Thus, lifetime chronic exposure to manganese from prenatal to older may be considered as a risk factor for development of parkinsonism [42]. Morphological, neurochemical, and behavioral alterations were reported in rat exposed to $\mathrm{MnCl}_{2} / \mathrm{Mn}(\mathrm{OAc})_{3}$ through inhalation route. These alterations were similar to those observed in PD [45]. Entering the brain, manganese gets accumulated in several regions particularly in globus pallidus, substantia nigra pars compacta, and other ganglia structures [46]. Manganism appears due to accumulation of manganese specifically in globus pallidus region of brain, whereas parkinsonism results from accumulation in other brain regions including globus pallidus and substantia nigra as depicted in Figure 1. Although globus pallidus is major site of Mn deposition in manganism but recent evidence suggests that Mn deposition may also occur in substantia nigra [47-49]. Substantia nigra is a specific brain region concerned with dopamine production. The progressive loss of dopaminergic neurons on manganese accumulation in this region is responsible for the pathophysiology of parkinsonism. PET neuroimaging studies carried out on animal models chronically exposed to $\mathrm{Mn}$ reported movement abnormalities in absence of nigrostriatal neuronal degeneration through inhibition of striatal dopamine release [50-52]. These studies revealed dysfunction of dopaminergic system in the cause of motor deficit. However, the detailed mechanism regarding whether Mn could have an impact on motor abnormalities in absence of dopaminergic neurodegeneration needs to addressed using advance molecular biology tools. The magnetic resonance imaging (MRI) of parkinsonism patients with history of exposure to manganese indicated the increased intensity in globus pallidum and substantia nigra regions of brain [53]. T1-weighted magnetic resonance imaging (MRI) and fluorodopa positron emission tomography (PET) scans of patients diagnosed with idiopathic parkinsonism, including the career welders, were carried out [54]. The results of the scans were found to be typical of idiopathic parkinsonism and were similar for both welder and nonwelder populations. Moreover the 6-(18F) fluorodopa PET scan of 43-year-old female parkinsonism patient was found to be abnormal while T1-weighted magnetic resonance imaging (MRI) of internal segment of the globus pallidum displayed increased signal [55]. These studies concluded that the manganese induced parkinsonism and Parkinson's disease share similar clinical and pathophysiological features.

\section{Oxidative Stress Mechanism in Manganese Neurotoxicity}

Manganese induced oxidative stress is known to cause dopaminergic cell death via apoptosis (Figure 2). The transport of manganese to cellular system occurs by simple diffusion processes. Other factors like diet such as body iron status may also determine the absorption of manganese $[56,57]$. There is an inverse relationship between the body iron status and manganese uptake since both compete for the same transport machineries such as transferrin/divalent metal transporter-1 (DMT1) [34, 57]. Various in vivo and in vitro cell models (representing central nervous system and brain) have been used to gain the mechanistic insight of manganese neurotoxicity. All these studies have identified the common signaling molecules such as $\operatorname{PKC} \delta$ that leads to apoptosis in these cellular systems [58]. Upon entering the cell Mn may have three cellular targets as shown in Figure 2. It may induce the endoplasmic reticulum stress and/or can accumulate in mitochondria and/or can cause the dopamine autooxidation. Mitochondria are an important cellular target in manganese neurotoxicity. Mitochondrial accumulation of manganese results in the inhibition of oxidative phosphorylation and generation of reactive oxygen species (ROS) [59]. Mn was found to interact with complex I and/or 


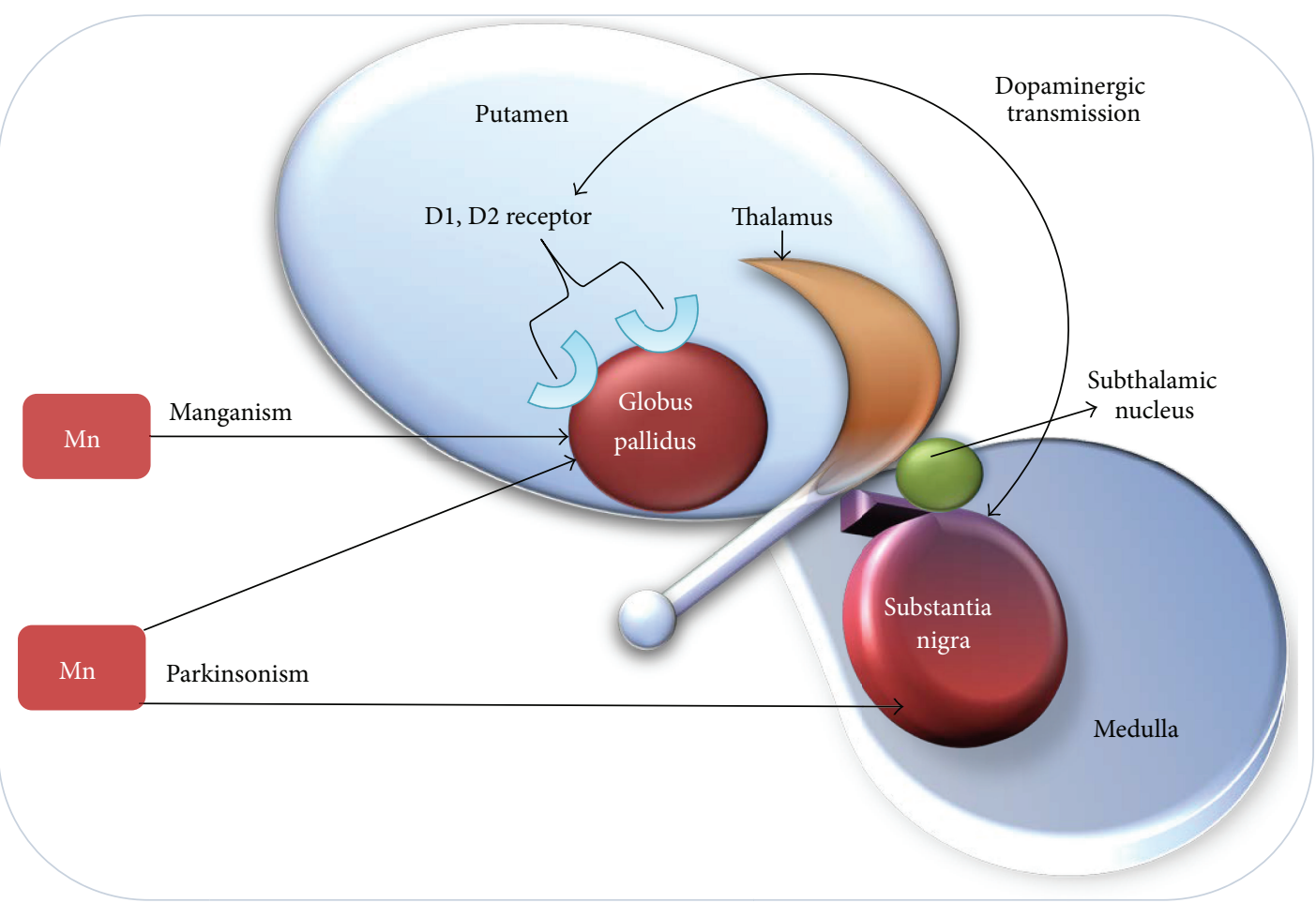

FIGURE 1: The specific regions of the brain influenced via manganese exposure depending on the level and potential of exposure. Globus pallidus is a major part of basal ganglia region of brain that includes substantia nigra. Dopamine is an important neurotransmitter, produced in the brain mainly by dopaminergic neurons in substantia nigra. The progressive loss of dopaminergic neurons due to manganese accumulation in substantia nigra over the prolonged exposure period leads to development of parkinsonism. Manganism happens on high acute exposure and accumulation of manganese, specifically in the globus pallidus.

complex II and F1ATPase and may also interfere with $\mathrm{Ca}^{2+}$ activated ATP production upon mitochondrial accumulation (Figure 2) [60-62]. The intramitochondrial $\mathrm{Ca}^{2+}$ regulates the rate of ATP production via binding a series of $\mathrm{Ca}^{2+}$-sensitive sites. $\mathrm{Ca}^{2+}$ activated dehydrogenases are associated with the Krebs cycle such as pyruvate dehydrogenase $(\mathrm{PDH})$, isocitrate dehydrogenase (ICDH), $\alpha$-ketoglutarate dehydrogenase $(\alpha \mathrm{KGDH})$, and F1F0 ATP synthase [63]. Mitochondrial accumulation of manganese was found to interfere with the $\mathrm{Ca}^{2+}$ activated ATP production through binding with $\mathrm{Ca}^{2+}$ sensitive sites in mitochondrial metabolic enzymes with more affinity than that of $\mathrm{Ca}^{2+}$ itself [64]. ATP is an important paracrine signaling molecule mediating the intracellular communication between the astrocytes through transmission of $\mathrm{Ca}^{2+}$ waves. $\mathrm{Ca}^{2+}$ signaling is a critical process for regulating the synaptic function, metabolism, and cerebral blood flow in central nervous system [65]. The neurodegenerative diseases such as Parkinson's and Alzheimer's diseases have been associated with dysfunction in the $\mathrm{Ca}^{2+}$ signaling [66]. Transient receptor potential channel TRPC3 was linked with pathophysiological activation of astrocytes [67]. Recently the ability of manganese to affect $\mathrm{Ca}^{2+}$ signaling was studied in striatal astrocytes and $\mathrm{Mn}$ was found to inhibit the $\mathrm{Ca}^{2+}$ influx in astrocytes through receptor potential channel TRPC3, most likely through competition for $\mathrm{Ca}^{2+}$ influx through these cation channels (Figure 2) [68]. However, more detailed electrophysiological studies are needed to precisely predict the mechanism through which manganese induced disruption of $\mathrm{Ca}^{2+}$ signaling in astrocytes.

Exposure to manganese causes the release of cytochrome $\mathrm{C}$ from mitochondria followed by subsequent loss of mitochondrial electrical potential (Figure 2). Cytochrome $\mathrm{C}$ can initiate a chain of molecular signaling events leading to caspase- 3 mediated apoptosis. Caspase- 3 is a key mediator of apoptosis and presumed to be activated downstream to cytochrome C. Protein kinase C (PKC $\delta$ ) has been identified as a proximal regulator of apoptosis [58]. Critical regulation of its cleavage and transportation to nucleus may determine the fate of cell survival or cell death. The nuclear transport of its activated form of cleaved product $(41 \mathrm{kDa})$ makes the cell irreversibly committed to apoptosis. The proapoptotic PKC $\delta$ $(74 \mathrm{kDa})$ is reported as a downstream substrate for caspase3 released from mitochondria as a result of mitochondrial damage (Figure 2). Caspase- 3 cleaves the PKC $\delta(74 \mathrm{kDa})$ to its proteolytic active product $\mathrm{PKC} \delta(41 \mathrm{kDa})$ that can translocate to nucleus and may cause the expression of proapoptotic genes $[58,69]$. Activation of PKC $\delta$ has been identified as a key event in the dopaminergic degeneration in animal PD models and apoptotic cell death of dopaminergic neuronal cells (N27) exposed to 6-hydroxydopamine (6-OHDA) [70]. Oxidative stress induced mitochondrial dysfunction upon 6OHDA exposure followed by release of caspase- 3 considered to be responsible for proteolytic activation of $\mathrm{PKC} \delta[70]$. 


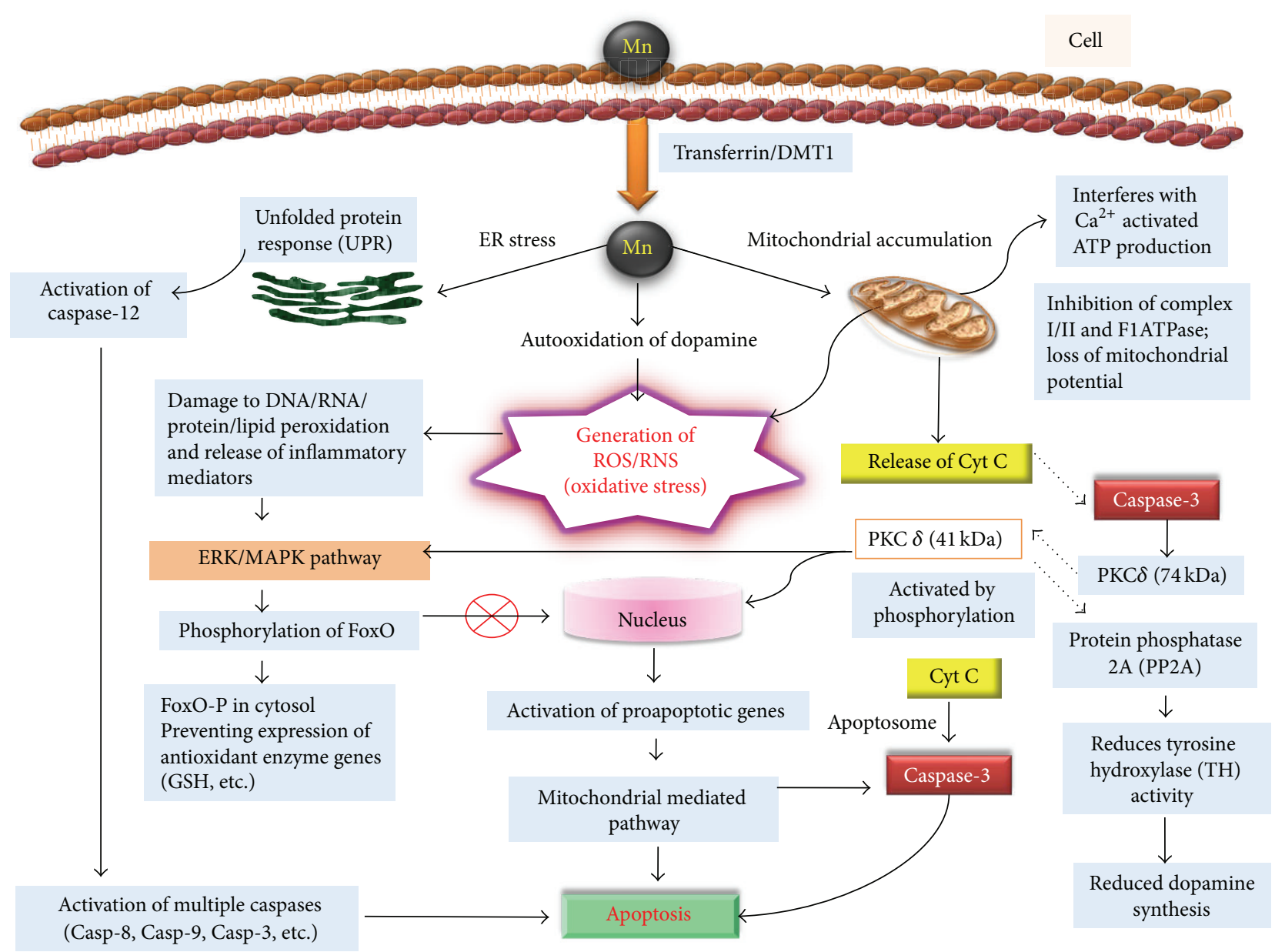

FIGURE 2: Schematic summarizing the oxidative stress mediated apoptotic pathway through which manganese causes the dopaminergic cell death and is involved in neurotoxic effects. Mn enters neuronal cells via transferrin/DMT1 receptor. Inside cell, Mn primarily gets accumulated in mitochondria causing inhibition of complex I/II and F1ATPase and interferes with $\mathrm{Ca}^{2+}$ activated ATP production. This resulted in loss of mitochondrial potential with release of Cyt C. Mitochondrial dysfunction also causes the generation of oxidative stress (ROS/RNS). The oxidative stress resulting from dopamine autooxidation causes damage to DNA/RNA/protein/lipid and releases inflammatory mediators that activate ERK/MAPK pathway. Activated kinase phosphorylates FoxO, preventing its translocation to nucleus and activation of antioxidant enzyme genes. Mn may also cause the endoplasmic reticulum (ER) stress that resulted in activation of caspase-12 through unfolded protein response. Caspase-12 may further activate the other downstream multiple caspases which culminates in apoptotic cell death. Cyt $\mathrm{C}$ released upon mitochondrial damage activates caspase-3, a critical regulator of apoptosis. Caspase-3 proteolytically activates the protein kinase $\mathrm{C} \delta$ $(\mathrm{PKC} \delta$ ) that again can activate ERK/MAPK pathway or on translocation to nucleus causes the expression of proapoptotic genes, resulting in mitochondrial mediated apoptotic cell death. Protein phosphatase $2 \mathrm{~A}$ is a downstream substrate for PKC $\delta$; activation of PP2A reduces the activity of tyrosine hydroxylase, inhibiting the dopamine production.

Protein phosphatase 2A (PP2A) is known to regulate the activity of tyrosine hydroxylase (TH) enzyme which is responsible for dopamine synthesis [71]. Recently both $\mathrm{TH}$ and PP2A were found to interact and colocalize with $\mathrm{PKC} \delta$. PKC $\delta$ may then phosphorylate PP2A to enhance its phosphatase activity. Increased PP2A activity dephosphorylates $\mathrm{TH}$-ser40 that reduces its enzymatic activity, thereby depleting dopamine in nitrostriatal neurons as a result of manganese exposure (Figure 2) [71]. The dopamine depletion is dependent on the concentration and duration of manganese exposure [72]. Recently zebrafish model of manganism was reported to decrease tyrosine hydroxylase in catecholaminergic nuclei of Mn exposed zebrafish larvae
[73]. These results are in agreement with previous in vitro studies. There has been a functional biphasic variation in $\mathrm{TH}$ activity depending on chronic or acute level of Mn exposure. Chronic exposure leads to decrease in TH activity while acute exposure causes increase in the $\mathrm{TH}$ activity. The biphasic variation in $\mathrm{TH}$ activity has also been reported in human Mn studies. Although the cause of biphasic variation is not known, it may be hypothesized to be related to $U$ shaped relations underlying deficiency and toxicity conditions, governed by dose and duration of exposure. Animal models may be used to investigate the detailed mechanism responsible for the cause of biphasic variation in $\mathrm{TH}$ activity. Inhibiting the $\mathrm{PKC} \delta$ function was found to restore $\mathrm{TH}$ and $\mathrm{PP} 2 \mathrm{~A}$ activities 
to normal, suggesting involvement of $\mathrm{PKC} \delta$-PP2A signaling pathway in manganese induced reduction in $\mathrm{TH}$ activity $[74,75]$. Manganese ions are required for PP2A phosphatase activity [76]. The release of Mn from PP2A active site by PP2A specific methylesterase leads to its inactivation.

Manganese has been reported to alter the catabolism of dopamine in dopaminergic cells [42, 77]. This causes the autooxidation of dopamine, contributing to the generation of reactive oxygen/nitrogen species ROS/RNS (Figure 2) [77, 78]. Free radicals cause structural and functional modifications of proteins DNA and RNA along with lipid peroxidation (F2-isoprostanes) $[62,79,80]$. Generation of free radicals causes release of inflammatory mediators like prostaglandin contributing to apoptotic cell death [81-83]. The pathways that resulted in oxidative stress, inflammation, and apoptosis upon Mn exposure are linked with each other and are responsible for the pathophysiology of neurodegenerative diseases [84]. MAPK kinase (ERK, JNK, and p38 MAPK) regulates a variety of cellular processes such as differentiation, proliferation, and inflammatory response by acting as connecting link between the extracellular signals and intracellular signaling pathway through intermediate signaling molecules [85]. ROS generated as a result of mitochondrial respiratory dysfunction on manganese exposure has been reported to trigger the activation of ERK and p38-MAPK analogous to that of ultraviolet radiation induced ROS generation and MAPK activation (Figure 2) [86-88]. Dopamine producing cells exposed to manganese has been reported to cause reduction in glutathione and glutathione peroxidase synthesis, an important antioxidant in cellular defense against oxidative stress $[3,68,89]$. SHSY5Y cells exposed to manganese were reported to cause oxidative DNA damage. These cells were found to be rescued when supplemented with antioxidants $\mathrm{N}$ acetyl cysteine and glutathione. This suggests the involvement of ROS and depletion of antioxidants in apoptotic cell death. Expression of antioxidant genes is tightly regulated inside the cell. A forkhead box transcription factor class $\mathrm{O}$ (FoxO) is a critical transcriptional factor that regulates these antioxidant genes [90]. Phosphorylation and dephosphorylation events of FoxO decide the fate of its activity. Dephosphorylated form is located in nucleus where it mediates the transcription of antioxidant/protective genes on manganese exposure. Recently FoxO has been reported as one of the downstream substrates for MAPK kinase in rat neonatal astrocyte cultures (Figure 2) [90]. Increased phosphorylation of FoxO prevents its translocation to cell nucleus, thus inhibiting the transcription of antioxidant genes contributing as one of the factors to the chain of events which results in neuronal cell death [91]. Recently C. elegans models of manganism have reported that the loss of glutathione S-transferase (GST1) associated with increased loss of dopaminergic neurons and neurodegeneration [8]. The other downstream substrate for PKC $\delta$ mediated apoptotic cell death has not been yet identified but it has been proposed that factors such as DNA protein kinase (DNA-PK), MAP-kinase, scramblase, and NFkappa transcription factor may be involved in this process [92-94].

Manganese exposure was found to cause endoplasmic reticulum (ER) stress in nigral dopaminergic neuronal cells
SN4741. The ER stress results in the upregulation of unfolded protein response genes such as $\mathrm{BiP}$ and activation of caspase12 (Figure 2) [95]. Caspase-12 subsequently activates multiple downstream caspases (Casp-8, Casp-9, Casp-1, and Casp-3) which leads to apoptosis in SN4741 cells. Manganese exposed T98G cells have shown significant upregulation of caspase3 in proportion to that of elevated DNA fragmentation [96]. The mechanism that causes ER stress and caspase-12 mediated activation of multiple caspases in response to manganese exposure is not being studied. However overexpression of $\mathrm{Bcl}-2$ in these cells has been shown to have neuroprotective function that confirms the role of caspases in neuronal cell death.

1-Methyl-4-phenyl-1-2-3-6-tetrahydropyridine (MPTP) is a precursor to 1-methyl-4-phenylpyridinium $\left(\mathrm{MPP}^{+}\right)$, a known neurotoxin responsible for causing the death of dopaminergic neurons in substantia nigra of brain and inducing permanent symptoms of Parkinson's disease [97]. Manganese treated PC12 cells have shown similar effects and mode of action to that observed with MPTP exposure [87]. Majority of in vitro studies have focused on the effect of manganese exposure on dopaminergic system while relatively few studies have considered nondopaminergic system [91]. Divalent metal transporter-1 (DMT1) is major transporter protein for manganese and is reported to be present in inner ear cells $[98,99]$ although the exact cellular location of DMT1 is still not determined. Manganese was reported to be toxic for neurons and sensory cells in cochlear cultures from postnatal rats suggesting that hearing deficit may occur with excess manganese exposure [100].

3.1. Oxidative Stress Influencing Epigenetic Regulation. Recent studies have focused on the epigenetic mechanisms that can modify the regulation of gene expression. Epigenetic alterations do not involve the change in nucleotide sequence but rather influence the process that governs gene expression. The epigenetic processes that have been recognized to regulate gene expression are DNA methylation and histone modification along with miRNAs that act at posttranscriptional level. DNA methylation in conjugation with histone modification controls the accessibility of transcription factors to promoter region of genes. There is growing evidence suggesting the implication of epigenetic mechanisms in susceptibility and progression of environmental toxicants induced diseases $[101,102]$. Epigenetic mechanism has been also reported to be responsible for causing various neurological disorders [15]. Upon manganese exposure, oxidative stress mediated apoptotic cell death has been well recognized mechanism for neuronal cell death. Generation of oxidative stress and its influence on epigenetic regulation have been investigated in several in vitro and in vivo models but not in the context with manganese induced neurotoxicity.

Exposure to various heavy metals including $\mathrm{As}, \mathrm{Pb}$, $\mathrm{Cd}$, and $\mathrm{Ni}$ has been reported to alter DNA methylation levels [103]. Heavy metal exposure generates reactive oxygen species through redox cycling [104]. Inhibition of antioxidant defense system may further potentiate ROS induced oxidative damage as reported and already discussed in relevance to manganese exposure in the previous section. The DNA 
lesions such as base modifications, deletions, and chromosome rearrangements caused by oxidative stress may interfere with ability of DNA methyltransferase to use DNA as a substrate, altering the global or gene specific methylation [105-107]. Alternations in DNA methylation mostly occur at $\mathrm{CpG}$ sites situated at the promoter region of genes. Methyl group in 5-methylcytosine has role in binding to transcriptional factors and transcriptional repressor methylCpG binding protein 2 (MeCP2) in sequence specific DNA protein interactions [108-110]. DNA methylation at CpG sites either prevents binding of transcription activators or recruits the transcriptional repressor ( $\mathrm{MeCP} 2)$ that may alter gene expression by interacting with histone deacetylase (HDAC). DNA methylation in association with histone deacetylase mediates repression of gene expression by generating the heterochromatin regions that result in potential heritable epigenetic alterations. 5-Methylcytosine is prone to oxidation and hydroxymethylcytosine is formed as a result of methylation. This reverses the binding of $\mathrm{MeCP} 2$ and further steps in chromatin condensation and silencing of gene expression [111]. ROS induced oxidative DNA damage leads to the global hypomethylation at $\mathrm{CpG}$ sites [112]. The global DNA methylation level was found to be increased in BEAS-2B cell exposed to $150 \mu \mathrm{M} \mathrm{H}_{2} \mathrm{O}_{2}$ for 3 days [113]. Additionally, BEAS-2B cells chronically exposed to arsenic were reported to induce ROS and promote tumorigenesis via downregulation of miR-199a-5p [114]. HIF- $1 \alpha$ and COX2 are identified as the downstream targets of miR-199a-5p [113]. The activation of HIF- $1 \alpha$ via epigenetic mechanism was found to be associated with the occurrence of several types of cancer $[115,116]$. Hypermethylation of glutathioneS-transferase P1 (GSTP1) gene was reported in intraepithelial neoplasia (HG-PIN) that makes the cells more susceptible to oxidative stress mediated DNA damage [117]. Gene specific promoter methylation in response to oxidative stress has been reported in the tumor suppressor gene RUNX3 [107, 118]. Methylation of E-cadherin promoter was reported in human colorectal and hepatocellular carcinoma cells [119]. Methyl-CpG binding protein 2 (MeCP2) is key contributor in epigenetic silencing of genes. $\mathrm{MeCP} 2$ gene mutation has been reported to cause neurodevelopmental disorder (Rett syndrome) [107]. The MeCP2 gene promoters have been found to be heavily hypermethylated in neuronal tissues. These results were confirmed by chromatin immunoprecipitation with anti-MeCP2 antibody in mice neuronal tissue cells [120]. The reactive oxygen species (ROS) generated as a result of iron sulfate or aluminum sulfate exposure have been reported to cause the upregulation of miRNAs, such as miR-9, miR-125b, and miR-128, in in vitro cell models [121]. Histone methylations primarily, histone $\mathrm{H} 3$ and histone $\mathrm{H} 4$, were among the important epigenetic modifications [122]. Recently, oxidative stress generated through occupational exposure to arsenic was reported to increase $\mathrm{H} 3 \mathrm{~K} 4 \mathrm{me} 2$ leading to transcriptionally active euchromatin regions [123]. This suggests the influence of oxidative stress on epigenetic regulation in cells. The histone deacetylase such as HDAC3 was found to be susceptible to oxidative damage. Thus oxidative stress mediated loss of activity may affect the global histone deacetylation [80]. Recent studies in context with alteration of epigenetic mechanism in response to environmental toxicants entail the contribution of oxidative stress as probable factor in mediating epigenetic changes [123].

These studies firmly confirm the ability of oxidative stress to deregulate the epigenetic mechanism of gene regulation. Oxidative stress mediated mechanism has been well established in manganese induced neurotoxicity; however the potential involvement of epigenetic deregulation has not been addressed. Studies involving the impact of Mn exposure on epigenetic regulation are not available. Hence at present, in-depth investigation is required on the oxidative stress mediated epigenetic alteration upon manganese exposure. This will facilitate better understanding of the potential role of epigenetic mechanism in manganese induced neurotoxicity.

\section{Epigenetics of Parkinson's Disease}

Parkinson's disease (PD) is amongst the common and well known neurodegenerative diseases mostly characterized by the presence of Lewy bodies in dopaminergic neuronal cells. $\mathrm{PD}$ is described as the idiopathic syndrome of parkinsonism. However, studies have correlated the occurrence of PD with the inheritance of defective genetic signatures [124, 125]. Generation of oxidative stress, mitochondrial dysfunction leading to energy imbalance, and defective ubiquitin mediated proteasomal cellular pathways has been identified to be responsible for PD [126]. A recent study entails that environmental pollutant induced epigenetic modifications are capable of bringing the perturbation to gene expression as similar to that observed with pathogenic gene mutations in PD [92]. Long term chronic exposure to certain metals like copper and manganese individually or in combination has been significantly found to be connected with increased risk of Parkinson's disease $[9,127]$. At cellular level PD is often characterized by eosinophilic Lewy bodies in dopaminergic neurons of substantia nigra of the brain consisting of aggregates of normal and misfolded proteins [128]. Recently, mutation in parkin gene was reported in PD patients of south India, without the development of Lewy bodies [129]. Clinical symptoms of PD are observed through progressive loss of dopaminergic neurons followed by reduced secretion of dopamine [130]. Mn exposure causes reduced secretion of dopamine through PKC $\delta$-PP2A signaling via inhibiting the $\mathrm{TH}$ activity. This finding supports the definitive role of environmental Mn exposure in etiology of PD. However review paper by Guilarte raises controversy against the similarities between manganese induced parkinsonism and idiopathic Parkinson's disease [131]. The hypothesis of the review was based on the studies performed on IPD patients to their response to levodopa therapy at different time period during the course of disease. Hence direct correlation between manganese induced parkinsonism and IPD may be problematic. Familial cases of PD associated with genetic mutation in SNCA, parkin, UCHL-1, PINK1, DJ1, and LRKK2 genes contribute only $5-10 \%$ of PD cases while the majority of PD cases are idiopathic [132, 133]. Recessive mutation to other PD linked genes such as parkin/PARK2 and DJ1 leads to loss of their functions and is reported to be responsible for early onset of parkinsonism [134]. Parkin 


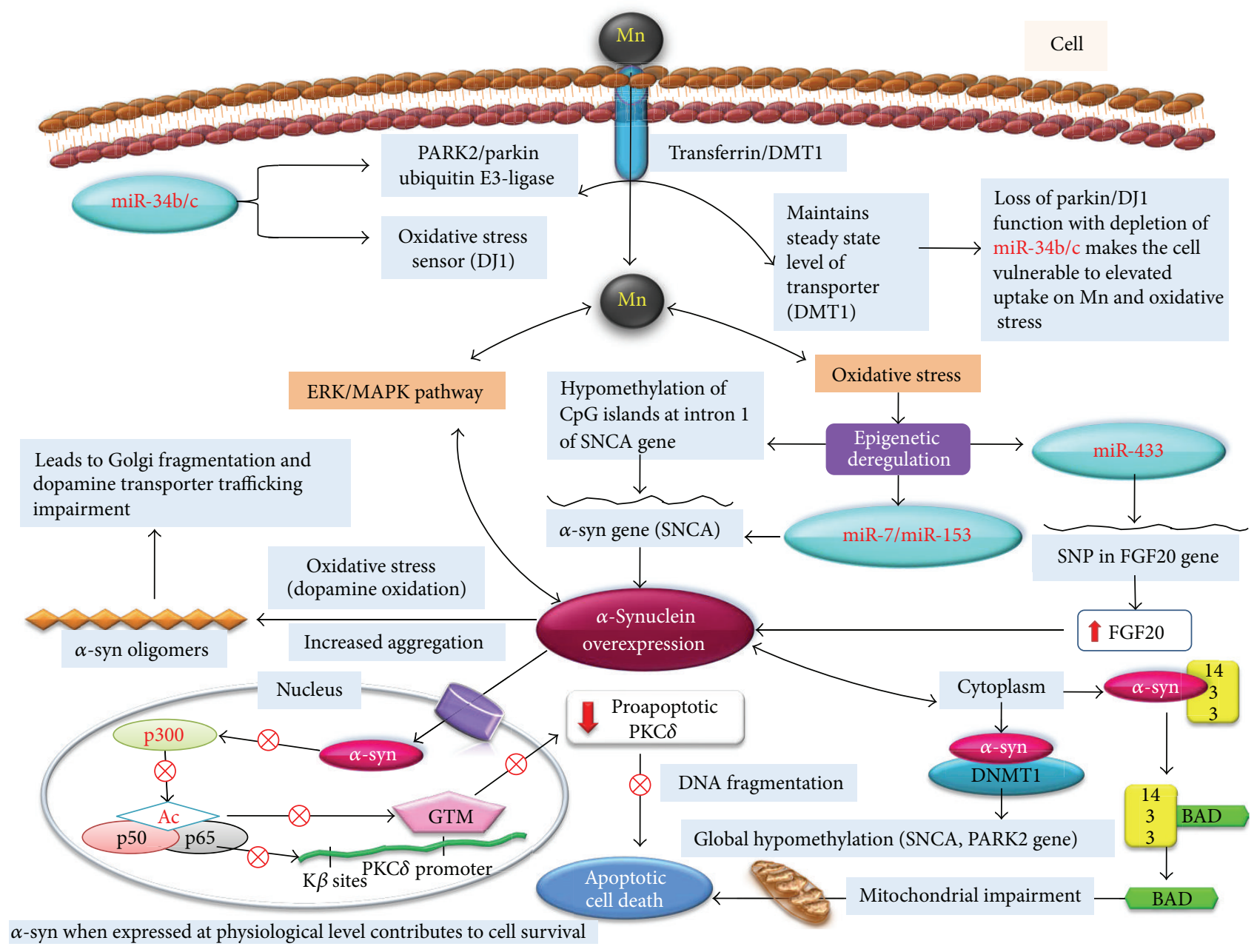

FIGURE 3: Schematic shows the potential role of epigenetic mechanism that may be involved in manganese induced chronic neurotoxic effects and in pathology of Parkinson's disease. The steady state level of Mn transporter (DMT1) is maintained by PARK2/parkin ubiquitin E3-ligase. $\mathrm{miR}-34 \mathrm{~b} / \mathrm{c}$ regulates the expression of PARK2. Loss of its expression can make the cells susceptible to elevated uptake of Mn. DJ1 works as an oxidative stress sensor which is again regulated by miR-34b/c; hence deregulation in miR-34b/c expression can make the cell vulnerable to oxidative stress. Mn induced oxidative stress causes the overexpression of $\alpha$-synuclein via ERK/MAPK pathway or through epigenetic alteration in miR-7/miR-153 expression which regulates $\alpha$-syn gene. Oxidative stress may also cause the hypomethylation of CpG islands at intron 1 of SNCA gene resulting in $\alpha$-synuclein overexpression. Expression of $\alpha$-synuclein is regulated by fibroblast growth factor 20 (FGF20) which is in turn regulated by miR-433. The single nucleotide polymorphism (SNP) at binding site of miR-433 disturbs epigenetic regulation of FGF2 0 causing $\alpha$-synuclein overexpression. $\alpha$-Synuclein under the influence of oxidative stress can form $\alpha$-syn oligomers which leads to Golgi complex fragmentation and subsequent impairment in dopamine transporter biosynthesis and trafficking. $\alpha$-Synuclein at cytoplasm binds to antiapoptotic 14-3-3, making proapoptotic BAD cause mitochondrial impairment. $\alpha$-Synuclein is reported to sequester DNMT1 in cytoplasm which results in global hypomethylation of genes including those associated with Parkinson's disease (SNCA, PARK2, etc.). $\alpha$-Synuclein expressed at physiological level is supposed to participate in cell survival via regulating proapoptotic PKC $\delta$ expression through epigenetic mechanism. $\alpha$-Synuclein at nucleus binds to histone proteins and inhibits activity of histone acetyltransferase, causing deregulation of PKC $\delta$ expression. The inhibition of PKC $\delta$ expression resulted in DNA fragmentation followed by apoptotic cell death.

is E3 ubiquitin ligase that regulates protein functions via targeting them for proteasomal degradation [134]. Figure 3 entails the molecular (genetic/epigenetic) events involved during the development of PD. Divalent metal transporter DMT1 has broad specificity for transport of metal ions but plays a significant role in transport of manganese $[135,136]$. DMT1 is a substrate for parkin and hence is involved in maintaining steady state level of this transporter [137]. Loss of parkin function makes the cell susceptible to elevated uptake of manganese [138]. DJ1 function is an oxidative stress sensor in neuronal cells of brain. The inactive oxidized form of DJ1 was found to be elevated in sporadic PD brain patients [139]. Inactivation of DJ1 can make the cell more vulnerable to the oxidative stress induced neuronal cell death (Figure 3) [140]. Simultaneous miRNA analysis in differentiated SHSY5Y cell line and PD brain samples revealed depletion or reduction in miR-34b/c [141, 142]. Further, this reduction was found to be associated with reduced parkin and DJ1 protein expression [143]. This suggests the adverse effect of manganese exposure on epigenetic mechanism. Dysregulation in 
parkin and DJ1 function makes the cell prone to oxidative stress and mitochondrial dysfunction that compromises cell viability as shown in Figure $3[144,145]$. However, the components of mitochondrial proteins that are modulated by miR-34b/c disruption need to be identified. Related studies have demonstrated that overexpressing parkin and PD linked genes can eliminate the $\alpha$-syn induced neurotoxicity. It was found that E3-ligase activity of parkin is responsible for degradation of $\alpha$-syn [146]. The release of cytochrome C from mitochondria as a result of mitochondrial membrane disruption is crucial for initiation of apoptosis. Recently parkin has been reported to inversely affect the release of cytochrome C and mitochondrial function in SH-SY5Y cells along with murine and fly models of parkin deficiency [145, $147,148]$.

Alpha-synuclein ( $\alpha$-syn) is small soluble protein $(14 \mathrm{kDa})$ expressed primarily at presynaptic terminals and is natively unfolded, although it gets folded when associated with membrane and when binding lipid molecules $[149,150] . \alpha$ syn has gathered considerably much interest in recent years as alteration in its gene expression was reported to be involved in the cause of several neurodegenerative diseases including Parkinson's disease [151, 152]. In vitro investigations have revealed that $\alpha$-syn is a major component of Lewy bodies consisting of aggregates of $\alpha$-syn protofibril formed as a result of excessive oxidative stress generated through autooxidation of neurotransmitter dopamine [153-155]. Alpha-synuclein overexpression can significantly contribute to the increased risk of sporadic PD $[156,157]$. PD patient's brain samples have shown the hypomethylation of SNCA intron 1 correlating with an increased expression of $\alpha$-syn (Figure 3) [158-162]. Apart from DNA methylation, miRNAs were also reported to regulate the $\alpha$-syn expression at posttranscriptional level. Specifically miR-7 and miR-153 were reported to regulate $\alpha$ syn expression in worm $C$. elegans and PD patients brains (Figure 3) [163, 164]. Additionally, impairment in miR-64, miR-55, let-7, miR-10a, miR-10b, miR-132, miR-7, miR-153, and $\mathrm{miR}-435$ expressions in symptomatic transgenic PD mice and PD disease models was found to be linked with increased $\alpha$-syn level [163, 165-167]. FGF20 is a member of fibroblast growth factor family that regulates the development and function of central nervous system. Variation in miR-433 binding site of FGF20 resulted in overexpression of FGF20 [168]. Elevated FGF20 may be linked with increased $\alpha$-syn expression in PD patient brain (Figure 3) [169].

\section{Implication of Epigenetic Mechanism in Manganese Induced Parkinson's Disease}

$\alpha$-Synuclein has been known to play a significant role in the dopaminergic cell death as observed in Lewy body diseases such as Parkinson's disease $[170,171]$. The manganese exposure generates the oxidative stress and causes dopamine oxidation. Oxidative stress was also considered as a critical mediator of dopaminergic cell death in Parkinson's disease $[172,173]$. Exposure to manganese has been reported to cause overexpression of $\alpha$-synuclein in neuroblastoma cells ( $\mathrm{SH}$ SY5Y) and implicated to be involved in neuronal apoptosis
(Figure 3) $[18,174]$. However, the upstream mechanism leading to $\alpha$-synuclein overexpression in cells exposed to manganese is still unexplored. A recent finding has demonstrated the involvement of ERK1/ERK2 MAPK pathway responsible for $\alpha$-synuclein overexpression in PC12 cells exposed to manganese as shown in Figure 3 [17]. Hypomethylation of $\alpha$-synuclein gene promoter has been demonstrated to cause overexpression of $\alpha$-synuclein in PD and related disorder [162]. Thus it may be hypothesized that alterations in methylation pattern may be responsible for manganese induced $\alpha$ synuclein overexpression.

Overexpression of $\alpha$-synuclein may lead to the onset of apoptosis (Figure 3). Oxidative stress and neurotransmitter dopamine may contribute to the $\alpha$-synuclein aggregation in in vitro models. $\alpha$-Synuclein aggregation may further damage dopaminergic neurons in worm $C$. elegans $[151,175,176]$. $\alpha$ Synuclein aggregation was reported to impair the biosynthetic pathway for dopamine transporter biosynthesis and subsequent maturation and trafficking (Figure 3) [177]. $\alpha$ syn may form the oligomers under the influence of oxidative stress that may lead to the fragmentation of Golgi complex [177].

$\alpha$-Synuclein has been recognized to play dual role in neuronal cell. When expressed at normal physiological level $\alpha$-synuclein is neuroprotective while overexpression beyond a certain threshold level resulted in toxicity (Figure 3) [178]. The nuclear localization of $\alpha$-synuclein was reported to cause the downregulation of proapoptotic PKC $\delta$ (Figure 3) [179].

Oxidative stress was identified to be responsible for the nuclear translocation of $\alpha$-synuclein in dopaminergic cells [180]. Nuclear translocation of $\alpha$-synuclein has been shown to cause increased susceptibility to oxidative stress in MES23.5 cells [173]. NF- $\kappa$ B and p300 were designated as vital nuclear proteins, involved in the modulation of $\mathrm{PKC} \delta$ expression in dopaminergic neurons of $\alpha$-synuclein transgenic mice [181]. Expression of $\alpha$-synuclein at normal level protected neuronal cells against 1-methyl-4-phenylpyridinium $\left(\mathrm{MPP}^{+}\right)$ or rotenone toxicity [182]. Recent in vivo and in vitro studies provide evidence that $\alpha$-synuclein interacts with histone proteins (p300) and reduces its histone acetyltransferase activity. Subsequent activation of p65 suppresses the binding of general transcription machinery (GTM) to PKC $\delta$ promoter and represses its gene expression (Figure 3) [179, $181,183] . \mathrm{PKC} \delta$ is an oxidative stress kinase and a critical regulator of apoptosis in central nervous system, recognized as downstream substrate for caspase-3. Proteolytic activation of PKC $\delta$ was reported to be involved in the dopaminergic cell death in cellular models of Parkinson's disease [184-186]. The mechanism through which $\alpha$-synuclein interacts with and disrupts p300 acetyltransferase activity is not yet clear. However, administration of HDAC inhibitors was reported to restore the acetylation state and protect neuronal cells against $\alpha$-synuclein toxicity $[187,188]$. In another prime study, it was reported that overexpressed soluble $\alpha$-synuclein forms a complex with antiapoptotic $14-3-3$ protein in $54-83-\mathrm{kD}$ complex that makes neuronal cell vulnerable to mitochondrial apoptotic cell death (Figure 3) [155, 189].

Recent studies with human postpartum brain sample of PD patients and $\alpha$-synuclein transgenic mice models have 


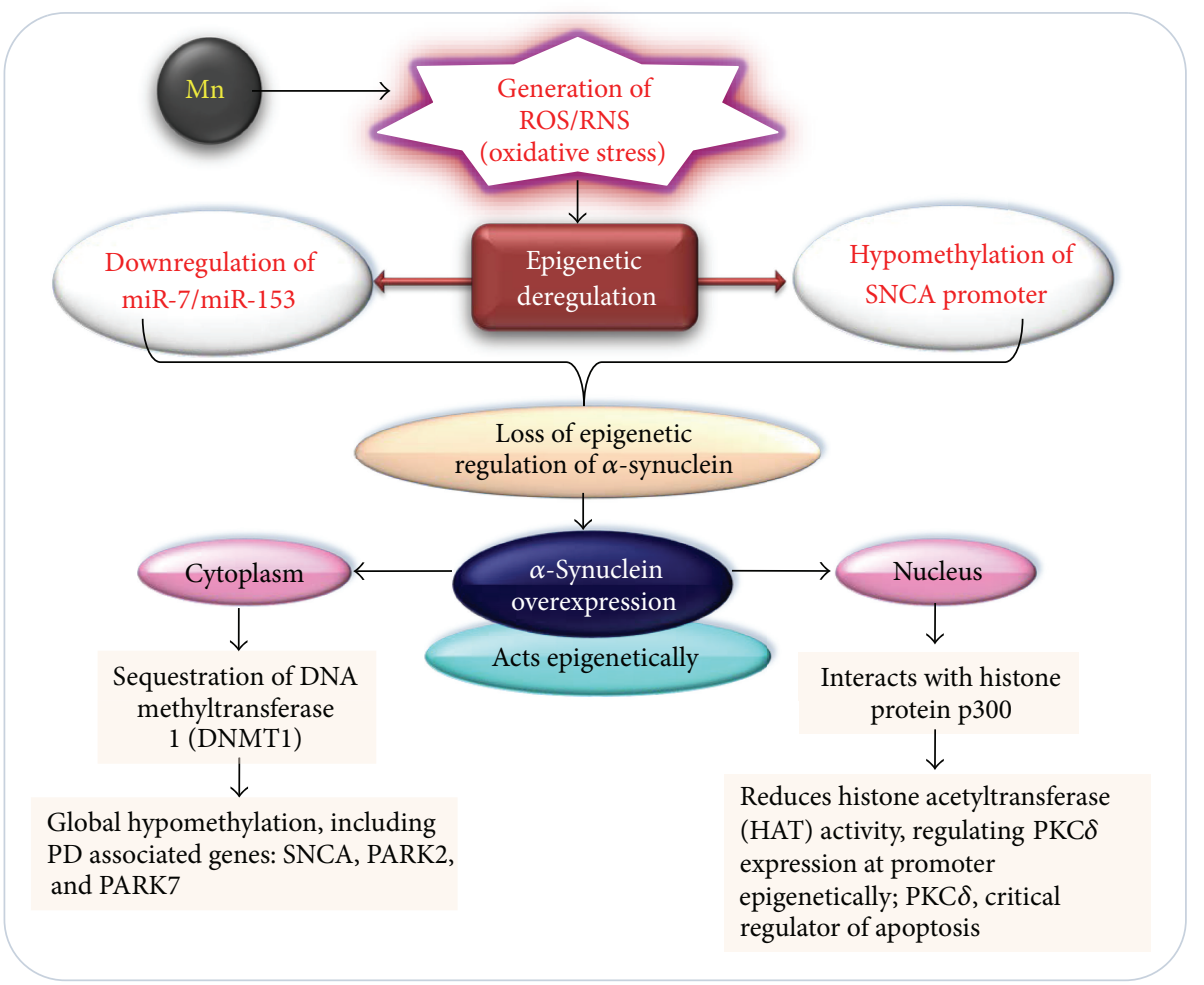

FIGURE 4: Schematic representing probable involvement of epigenetic deregulation caused by the overexpression of $\alpha$-synuclein in in vitro and in in vivo cell models of Parkinson's disease. The oxidative stress resulting from Mn exposure has a potential to alter epigenetic regulation of $\alpha$-synuclein via hypomethylation of SNCA gene promoter or through downregulation of miR-7/miR-153. Overexpressed $\alpha$-synuclein acts epigenetically via sequestration of DNA methyltransferase in cytoplasm. This causes the global change in DNA methylation profile of genes associated with PD. $\alpha$-Synuclein inside nucleus regulates the expression of PKC $\delta$ epigenetically, a proximal regulator of apoptosis. $\alpha$-Synuclein inhibits binding of protein transcriptional machinery to $\mathrm{PKC} \delta$ gene promoter region via binding histone protein p300 and inhibiting its histone acetyltransferase activity.

reported the association between DNA methyltransferase (DNMT1) and $\alpha$-synuclein, resulting in aberrant cytoplasmic localization of DNMT1 (Figure 4) $[155,189,190]$. Interaction of $\alpha$-synuclein with histone proteins and inhibition of its acetyltransferase activity suggest the direct role of histone proteins in epigenetic regulation (Figure 4).

The sequestration of DNMT1 in cytoplasm results in global DNA hypomethylation including PD associated genes such as SNCA, SEPW1, and PRKAR2A in both human and mice brain samples (Figure 4) [190]. Epigenetic mechanism including DNA methylation regulates the neuronal development and environmental factors were reported to interfere with the regulatory processes at epigenetic level [191, 192]. Developmental manganese exposure in mice was reported to affect neurogenesis in hippocampal dentate gyrus [193]. Global DNA methylation microarray profiling of hippocampal dentate gyrus following manganese exposure revealed hypermethylation of several genes involved in differentiation processes [194]. These findings suggest that deregulation of epigenetic mechanism could be a potential mediator that affects the hippocampal neurogenesis in response to the exposure to manganese. Chronic exposure to manganese has been reported to result in Parkinson's disease in both in vivo and in vitro cell models. In recent years, environmental epigenetic research has grown very rapidly. Various environmental pollutant induced diseases have been linked with disruption of epigenetic regulation. Manganese exposure could result in neuronal toxicity and neurodegenerative diseases. However, role of manganese induced epigenetic variation in context of neurodegenerative diseases needs to be further investigated. This will help us to develop suitable and effective prognostic and therapeutic approaches.

\section{Genetic Polymorphism in Epigenetic Susceptibility to Manganese Neurotoxicity}

Variation in DNA sequences, epigenetic mechanism, and environmental factors may act synergistically to contribute to the development of neuronal disorders. DNA methyltransferase (DNMT1) maintains the methylation pattern through generations, whereas the de novo DNMT (DNMT3A, DNMT3B) introduces the tissue specific methylation marks during the development or in response to environmental factors. Genetic polymorphism in DNMT could be the critical event in epigenetic susceptibility to environmentally induced 
chronic disease. Recently, a south Indian population was studied for genetic polymorphism in DNMT1, DNMT3A, DNMT3B, and DNMT3L for association with schizophrenia. The genetic variants in DNMT1, rs2114724 and rs2228611, were found to be significantly associated with schizophrenia while de novo DNMTs variants, DNMT3B rs2424932, DNMT3B rs156968, and DNMT3L rs2070565, were associated with early age onset of disease [195]. This study had demonstrated the role of genetic polymorphism in DNA methyltransferase and its association with individual methylation level and susceptibility. However, the studies pertaining to the identification of genetic susceptibility factors have been limited and invariantly inconsistent [195]. The individual differences at genetic level determine the response of individual to different environmental stimuli. These differences can be attributed to the variability in response of individuals, even experiencing a similar level of exposure. Epidemiological studies in recent years have reported the positive correlation between the single nucleotide polymorphisms (SNPs) in genes involved in manganese detoxification and differences in individual's susceptibility to manganism [196, 197]. The differences in individual genotypes might be responsible for the variability in blood manganese level of manganese miners experiencing the same exposure environment. It is evident that merely evaluating the blood manganese level in exposed population with individual genotypic difference may not predict the subjects who are more prone to manganese related neurological diseases. In agreement with the above findings, recently research group at our lab have studied the genetic polymorphism in cytochrome P450s, glutathione-Stransferases and $\mathrm{NAD}(\mathrm{P}) \mathrm{H}$, and quinone oxidoreductase in manganese miners of central Indian population [198]. The finding suggests the association between the cytochrome P450 CYP2D6 polymorphism and susceptibility to chronic manganism [198]. However, the mechanism by which variant of cytochrome P450 CYP2D6 has protective role in manganese susceptibility is not well understood. It might be attributed to perturbation in manganese metabolism or association with other polymorphic alleles of gene that may increase or decrease the enzymatic activity. It is evident from the study that cytochrome P450 CYP2D6 may be considered as a susceptibility biomarker for identifying the miners who are at higher risk for developing manganism. Iron and manganese are supposed to share similar transport and regulatory proteins. It is demonstrated that divalent metal transporter-1 (DMT1) mediates the transport of iron and manganese [199]. Recently, animal studies have found the inverse relationship between the body iron stores and absorption of manganese [34]. It was reported that deficiency of iron resulted in significant increase in manganese absorption and retention in various organs of laboratory animals models [57]. Hepcidin is a regulatory hormone, product of HEP gene that controls the iron absorption in response to total body iron status [200]. The variants of HEP genes, C282Y and H63D, have been reported to be associated with increased uptake of dietary iron [201]. Recent study has found that the individuals with variant of HEP gene had $12 \%$ lower blood manganese level in comparison to the wild-type subjects [202]. As discussed earlier that
FGF20 is a member of fibroblast growth family that regulates the development and function of central nervous system, it was demonstrated that variation in miR-435 binding site of FGF20 gene, due to single nucleotide polymorphism (SNP), resulted in the FGF20 overexpression [169]. Elevated level of FGF20 has been linked with overexpression of $\alpha$-syn, a characteristic of Parkinson's disease (Figure 3) $[169,196]$ although the mechanistic insight of the process that leads to $\alpha$-syn overexpression due to elevated FGF20 has not been investigated. However it is evident that the perturbation of epigenetic mechanism (miRNA binding site alteration in FGF20 gene) might be involved in manganese mediated overexpression of $\alpha$-syn, implicated in the development of Parkinson's disease. It may be suggested that the individuals in population having SNP in FGF20 may have altered epigenetic regulation of $\alpha$-syn. Hence these individuals might be predicted at higher risk of developing parkinsonism or other neurodegenerative disorders in response to environment or occupational manganese exposure. Epidemiological studies suggest the definitive link between the genetic polymorphism and epigenetic susceptibility to manganese neurotoxicity. The more comprehensive molecular approaches might give indepth understanding of the individual genetic differences to association with epigenetic susceptibility in relevance to manganese exposure.

\section{Conclusion}

Epigenetic signatures influenced by manganese exposure need to be studied to gain better understanding of the molecular pathway leading to neuronal cell death and its implication in Parkinson's disease. Most of the findings and interpretation on the mechanism of manganese induced neurotoxicity are based on the high exposure levels of manganese in experimental models, which is considered to induce manganism in humans. This exposure level should not be correlated with chronic low level lifetime exposure in humans. Further studies are needed to investigate whether the molecular pathways that are responsible for manganese induced dopaminergic cell death in humans are similar to those reported in scientific studies using in vivo/in vitro cell models. The single nucleotide polymorphism in genes determines the susceptibility level of an individual in response to toxicant exposure. How the epigenetics is linked with genetic susceptibility might be the exciting area of research to be investigated in future. The study of epigenetic mechanism may further elaborate the present knowledge about manganese neurotoxicity. The definitive pathways may be identified which can be used as target for disease progression and therapeutics in relevance to manganese exposure.

\section{Competing Interests}

The authors declare no competing interests.

\section{Acknowledgments}

The authors are thankful to CSIR-NEERI, Nagpur, India, for providing the necessary facilities. The authors are grateful 
to Integrated NextGen approaches in health, disease, and environmental toxicity (INDEPTH) networking project (BSC 0111) for providing necessary funding.

\section{References}

[1] G. C. Cotzias, "Manganese in health and disease," Physiological Reviews, vol. 38, no. 3, pp. 503-532, 1958.

[2] A. Takeda, "Manganese action in brain function," Brain Research Reviews, vol. 41, no. 1, pp. 79-87, 2003.

[3] K. M. Erikson, D. C. Dorman, L. H. Lash, and M. Aschner, "Manganese inhalation by rhesus monkeys is associated with brain regional changes in biomarkers of neurotoxicity," Toxicological Sciences, vol. 97, no. 2, pp. 459-466, 2007.

[4] C. Tamm, F. Sabri, and S. Ceccatelli, "Mitochondrial-mediated apoptosis in neural stem cells exposed to manganese," Toxicological Sciences, vol. 101, no. 2, pp. 310-320, 2008.

[5] J. M. Antonini, A. B. Santamaria, N. T. Jenkins, E. Albini, and R. Lucchini, "Fate of manganese associated with the inhalation of welding fumes: potential neurological effects," NeuroToxicology, vol. 27, no. 3, pp. 304-310, 2006.

[6] S. B. Goldhaber, "Trace element risk assessment: essentiality vs. Toxicity," Regulatory Toxicology and Pharmacology, vol. 38, no. 2, pp. 232-242, 2003.

[7] J. Rodier, "Manganese poisoning in Moroccan miners," British Journal of Industrial Medicine, vol. 12, no. 1, pp. 21-35, 1955.

[8] R. Settivari, N. VanDuyn, J. LeVora, and R. Nass, "The Nrf2/SKN-1-dependent glutathione S-transferase $\pi$ homologue GST-1 inhibits dopamine neuron degeneration in a Caenorhabditis elegans model of manganism," NeuroToxicology, vol. 38, pp. 51-60, 2013.

[9] J. M. Gorell, E. L. Peterson, B. A. Rybicki, and C. C. Johnson, "Multiple risk factors for Parkinson's disease," Journal of the Neurological Sciences, vol. 217, no. 2, pp. 169-174, 2004.

[10] J. M. Gorell, C. C. Johnson, B. A. Rybicki et al., "Occupational exposure to manganese, copper, lead, iron, mercury and zinc and the risk of Parkinson's disease," NeuroToxicology, vol. 20, no. 2-3, pp. 239-248, 1999.

[11] D. J. Betteridge, "What is oxidative stress?" Metabolism, vol. 49, no. 2, pp. 3-8, 2000.

[12] V. V. Dukhande, G. H. Malthankar-Phatak, J. J. Hugus, C. K. Daniels, and J. C. K. Lai, "Manganese-induced neurotoxicity is differentially enhanced by glutathione depletion in astrocytoma and neuroblastoma cells," Neurochemical Research, vol.31, no. 11, pp. 1349-1357, 2006.

[13] S. Orrenius, V. Gogvadze, and B. Zhivotovsky, "Mitochondrial oxidative stress: implications for cell death," Annual Review of Pharmacology and Toxicology, vol. 47, pp. 143-183, 2007.

[14] M. Schnekenburger, G. Talaska, and A. Puga, "Chromium crosslinks histone deacetylase 1-DNA methyltransferase 1 complexes to chromatin, inhibiting histone-remodeling marks critical for transcriptional activation," Molecular and Cellular Biology, vol. 27, no. 20, pp. 7089-7101, 2007.

[15] T. Abel and R. S. Zukin, "Epigenetic targets of HDAC inhibition in neurodegenerative and psychiatric disorders," Current Opinion in Pharmacology, vol. 8, no. 1, pp. 57-64, 2008.

[16] F. D. Dick, G. De Palma, A. Ahmadi et al., "Environmental risk factors for Parkinson's disease and parkinsonism: the Geoparkinson study," Occupational and Environmental Medicine, vol. 64, no. 10, pp. 666-672, 2007.
[17] T. Cai, T. Yao, G. Zheng et al., "Manganese induces the overexpression of $\alpha$-synuclein in PC12cells via ERK activation. Brain Research," Brain Research Bulletin, vol. 1359, pp. 201-210, 2010.

[18] Y. Li, L. Sun, T. Cai et al., “ $\alpha$-Synuclein overexpression during manganese-induced apoptosis in SH-SY5Y neuroblastoma cells," Brain Research Bulletin, vol. 81, no. 4-5, pp. 428-433, 2010.

[19] A. Baccarelli and V. Bollati, "Epigenetics and environmental chemicals," Current Opinion in Pediatrics, vol. 21, no. 2, pp. 243251, 2009.

[20] R. Lucchini and N. Zimmerman, "Lifetime cumulative exposure as a threat for neurodegeneration: need for prevention strategies on a global scale," NeuroToxicology, vol. 30, no. 6, pp. 1144-1148, 2009.

[21] K. S. Crump, "Manganese exposures in Toronto during use of the gasoline additive, methylcyclopentadienyl manganese tricarbonyl," Journal of Exposure Analysis and Environmental Epidemiology, vol. 10, no. 3, pp. 227-239, 2000.

[22] D. R. Lynam, J. W. Roos, G. D. Pfeifer, B. F. Fort, and T. G. Pullin, "Environmental effects and exposures to manganese from use of methylcyclopentadienyl manganese tricarbonyl (MMT) in gasoline," NeuroToxicology, vol. 20, no. 2-3, pp. 145-150, 1999.

[23] J. Zayed, M. Gerin, S. Loranger, P. Sierra, D. Begin, and G. Kennedy, "Occupational and environmental exposure of garage workers and taxi drivers to airborne manganese arising from the use of methylcyclopentadienyl manganese tricarbonyl in unleaded gasoline," American Industrial Hygiene Association Journal, vol. 55, no. 1, pp. 53-58, 1994.

[24] WHO, "Guidelines for Drinking-Water Quality," Incorporating First Addendum, 2006, http://www.who.int/water_sanitation_ health/dwq/gdwq0506begin.pdf.

[25] K. Ljung and M. Vahter, "Time to re-evaluate the guideline value for manganese in drinking water?" Environmental Health Perspectives, vol. 115, no. 11, pp. 1533-1538, 2007.

[26] M. F. Bouchard, S. Sauvé, B. Barbeau et al., "Intellectual impairment in school-age children exposed to manganese from drinking water," Environmental Health Perspectives, vol. 119, no. 1, pp. 138-143, 2011.

[27] R. Sharma and S. Pervez, "Toxic metals status in human blood and breast milk samples in an integrated steel plant environment in Central India," Environmental Geochemistry and Health, vol. 27, no. 1, pp. 39-45, 2005.

[28] ATSDR, Toxicological Profile for Manganese, United States Department of Health and Human Services, Atlanta, Ga, USA, 2012.

[29] K. A. Cockell, G. Bonacci, and B. Belonje, "Manganese content of soy or rice beverages is high in comparison to infant formulas," Journal of the American College of Nutrition, vol. 23, no. 2, pp. 124-130, 2004.

[30] A. W. Dobson, K. M. Erikson, and M. Aschner, "Manganese neurotoxicity," Annals of the New York Academy of Sciences, vol. 1012, pp. 115-128, 2004.

[31] J. R. Roede, J. M. Hansen, Y.-M. Go, and D. P. Jones, “Maneb and paraquat-mediated neurotoxicity: involvement of peroxiredoxin/thioredoxin system," Toxicological Sciences, vol. 121, no. 2 , pp. 368-375, 2011.

[32] B. Ritz and F. Yu, "Parkinson's disease mortality and pesticide exposure in California 1984-1994," International Journal of Epidemiology, vol. 29, no. 2, pp. 323-329, 2000.

[33] D. A. Drechsel and M. Patel, "Role of reactive oxygen species in the neurotoxicity of environmental agents implicated in 
Parkinson's disease," Free Radical Biology and Medicine, vol. 44, no. 11, pp. 1873-1886, 2008.

[34] K. Thompson, R. Molina, T. Donaghey, J. D. Brain, and M. Wessling-Resnick, "The influence of high iron diet on rat lung manganese absorption," Toxicology and Applied Pharmacology, vol. 210, no. 1-2, pp. 17-23, 2006.

[35] M. M. Finkelstein and M. Jerrett, "A study of the relationships between Parkinson's disease and markers of traffic-derived and environmental manganese air pollution in two Canadian cities," Environmental Research, vol. 104, no. 3, pp. 420-432, 2007.

[36] E. L. Lucas, P. Bertrand, S. Guazzetti et al., "Impact of ferromanganese alloy plants on household dust manganese levels: implications for childhood exposure," Environmental Research, vol. 138, pp. 279-290, 2015.

[37] G. A. Wasserman, X. Liu, F. Parvez et al., "Water manganese exposure and children's intellectual function in Araihazar, Bangladesh," Environmental Health Perspectives, vol. 114, no. 1, pp. 124-129, 2006.

[38] B. A. Racette, S. R. Criswell, J. I. Lundin et al., "Increased risk of parkinsonism associated with welding exposure," NeuroToxicology, vol. 33, no. 5, pp. 1356-1361, 2012.

[39] S. R. Criswell, J. S. Perlmutter, T. O. Videen et al., "Reduced uptake of $\left[{ }^{18} \mathrm{~F}\right]$ FDOPA PET in asymptomatic welders with occupational manganese exposure," Neurology, vol. 76, no. 15, pp. 1296-1301, 2011.

[40] S. R. Criswell, J. S. Perlmutter, J. L. Huang et al., "Basal ganglia intensity indices and diffusion weighted imaging in manganeseexposed welders," Occupational and Environmental Medicine, vol. 69, no. 6, pp. 437-443, 2012.

[41] R. G. Lucchini, E. Albini, L. Benedetti et al., "High prevalence of Parkinsonian disorders associated to manganese exposure in the vicinities of ferroalloy industries," American Journal of Industrial Medicine, vol. 50, no. 11, pp. 788-800, 2007.

[42] R. G. Lucchini, S. Guazzetti, S. Zoni et al., "Neurofunctional dopaminergic impairment in elderly after lifetime exposure to manganese," NeuroToxicology, vol. 45, pp. 309-317, 2014.

[43] WHO, Manganese. Environmental Health Criteria 17, World Health Organization, Geneva, Switzerland, 1981.

[44] D. A. Cory-Slechta, "Studying toxicants as single chemicals: does this strategy adequately identify neurotoxic risk?" NeuroToxicology, vol. 26, no. 4, pp. 491-510, 2005.

[45] J. Sanchez-Betancourt, V. Anaya-Martínez, A. L. GutierrezValdez et al., "Manganese mixture inhalation is a reliable Parkinson disease model in rats," NeuroToxicology, vol. 33, no. 5, pp. 1346-1355, 2012.

[46] M. Yamada, S. Ohno, I. Okayasu et al., "Chronic manganese poisoning: a neuropathological study with determination of manganese distribution in the brain," Acta Neuropathologica, vol. 70, no. 3-4, pp. 273-278, 1986.

[47] Y. Choi, J. K. Park, N. H. Park et al., "Whole blood and red blood cell manganese reflected signal intensities of T1-weighted magnetic resonance images better than plasma manganese in liver cirrhotics," Journal of Occupational Health, vol. 47, no. 1, pp. 68-73, 2005.

[48] J. D. Park, Y. H. Chung, C. Y. Kim et al., "Comparison of high MRI T1 signals with manganese concentration in brains of cynomolgus monkeys after 8 months of stainless steel weldingfume exposure," Inhalation Toxicology, vol. 19, no. 11, pp. 965971, 2007.

[49] J. A. Roth and M. D. Garrick, "Iron interactions and other biological reactions mediating the physiological and toxic actions of manganese," Biochemical Pharmacology, vol. 66, no. 1, pp. 1-13, 2003.

[50] T. R. Guilarte, M.-K. Chen, J. L. McGlothan et al., "Nigrostriatal dopamine system dysfunction and subtle motor deficits in manganese-exposed non-human primates," Experimental Neurology, vol. 202, no. 2, pp. 381-390, 2006.

[51] T. R. Guilarte, N. C. Burton, J. L. McGlothan et al., "Impairment of nigrostriatal dopamine neurotransmission by manganese is mediated by pre-synaptic mechanism(s): implications to manganese-induced parkinsonism," Journal of Neurochemistry, vol. 107, no. 5, pp. 1236-1247, 2008.

[52] T. M. Peneder, P. Scholze, M. L. Berger et al., "Chronic exposure to manganese decreases striatal dopamine turnover in human alpha-synuclein transgenic mice," Neuroscience, vol. 180, pp. 280-292, 2011.

[53] Y. Kim, J.-M. Kim, J.-W. Kim et al., "Dopamine transporter density is decreased in Parkinsonian patients with a history of manganese exposure: what does it mean?" Movement Disorders, vol. 17, no. 3, pp. 568-575, 2002.

[54] B. A. Racette, L. McGee-Minnich, S. M. Moerlein, J. W. Mink, T. O. Videen, and J. S. Perlmutter, "Welding-related parkinsonism: clinical-features, treatment, and pathophysiology," Neurology, vol. 56, no. 1, pp. 8-13, 2001.

[55] W. C. Koller, K. E. Lyons, and W. Truly, "Effect of levodopa treatment for parkinsonism in welders: a double-blind study," Neurology, vol. 62, no. 5, pp. 730-733, 2004.

[56] J. A. Garcia-Aranda, R. A. Wapnir, and F. Lifshitz, "In vivo intestinal absorption of manganese in the rat," The Journal of Nutrition, vol. 113, no. 12, pp. 2601-2607, 1983.

[57] S. J. Garcia, K. Gellein, T. Syversen, and M. Aschner, "Iron deficient and manganese supplemented diets alter metals and transporters in the developing rat brain," Toxicological Sciences, vol. 95, no. 1, pp. 205-214, 2007.

[58] C. Latchoumycandane, V. Anantharam, M. Kitazawa, Y. Yang, A. Kanthasamy, and A. G. Kanthasamy, "Protein kinase $\mathrm{C} \delta$ is a key downstream mediator of manganese-induced apoptosis in dopaminergic neuronal cells," Journal of Pharmacology and Experimental Therapeutics, vol. 313, no. 1, pp. 46-55, 2005.

[59] Y. Chtourou, K. Trabelsi, H. Fetoui, G. Mkannez, H. Kallel, and N. Zeghal, "Manganese induces oxidative stress, redox state unbalance and disrupts membrane bound ATPases on murine neuroblastoma cells in vitro: protective role of silymarin," Neurochemical Research, vol. 36, no. 8, pp. 1546-1557, 2011.

[60] C. E. Gavin, K. K. Gunter, and T. E. Gunter, "Manganese and calcium transport in mitochondria: implications for manganese toxicity," NeuroToxicology, vol. 20, no. 2-3, pp. 445-454, 1999.

[61] Y. Kushnareva, A. N. Murphy, and A. Andreyev, "Complex I-mediated reactive oxygen species generation: modulation by cytochrome c and $\mathrm{NAD}(\mathrm{P})+$ oxidation-reduction state," Biochemical Journal, vol. 368, no. 2, pp. 545-553, 2002.

[62] J. Bornhorst, S. Meyer, T. Weber et al., "Molecular mechanisms of Mn induced neurotoxicity: RONS generation, genotoxicity, and DNA-damage response," Molecular Nutrition and Food Research, vol. 57, no. 7, pp. 1255-1269, 2013.

[63] R. S. Balaban, "Cardiac energy metabolism homeostasis: role of cytosolic calcium," Journal of Molecular and Cellular Cardiology, vol. 34, pp. 11259-11271, 2002.

[64] T. E. Gunter, C. E. Gavin, M. Aschner, and K. K. Gunter, "Speciation of manganese in cells and mitochondria: a search for the proximal cause of manganese neurotoxicity," Neurotoxicology, vol. 27, pp. 765-776, 2006. 
[65] P. G. Haydon and G. Carmignoto, "Astrocyte control of synaptic transmission and neurovascular coupling," Physiological Reviews, vol. 86, no. 3, pp. 1009-1031, 2006.

[66] G. Burnstock, U. Krügel, M. P. Abbracchio, and P. Illes, "Purinergic signalling: from normal behaviour to pathological brain function," Progress in Neurobiology, vol. 95, no. 2, pp. 229274, 2011.

[67] H. Shirakawa, "Pathophysiological significance of canonical transient receptor potential (TRPC) subfamily in astrocyte activation," Yakugaku Zasshi, vol. 132, no. 5, pp. 587-593, 2012.

[68] K. M. Streifel, J. Miller, R. Mouneimne, and R. B. Tjalkens, "Manganese inhibits ATP-induced calcium entry through the transient receptor potential channel TRPC3 in astrocytes," NeuroToxicology, vol. 34, no. 1, pp. 160-166, 2013.

[69] M. Kitazawa, V. Anantharam, Y. Yang, Y. Hirata, A. Kanthasamy, and A. G. Kanthasamy, "Activation of protein kinase $\mathrm{C} \delta$ by proteolytic cleavage contributes to manganese-induced apoptosis in dopaminergic cells: protective role of Bcl-2," Biochemical Pharmacology, vol. 69, no. 1, pp. 133-146, 2005.

[70] C. Latchoumycandane, V. Anantharam, H. Jin, A. Kanthasamy, and A. Kanthasamy, "Dopaminergic neurotoxicant 6-OHDA induces oxidative damage through proteolytic activation of PKC $\delta$ in cell culture and animal models of Parkinson's disease," Toxicology and Applied Pharmacology, vol. 256, no. 3, pp. 314323, 2011.

[71] D. Zhang, A. Kanthasamy, V. Anantharam, and A. Kanthasamy, "Effects of manganese on tyrosine hydroxylase (TH) activity and TH-phosphorylation in a dopaminergic neural cell line," Toxicology and Applied Pharmacology, vol. 254, no. 2, pp. 6571, 2011.

[72] M. Kitazawa, J. R. Wagner, M. L. Kirby, V. Anantharam, and A. G. Kanthasamy, "Oxidative stress and mitochondrial-mediated apoptosis in dopaminergic cells exposed to methylcyclopentadienyl manganese tricarbonyl," Journal of Pharmacology and Experimental Therapeutics, vol. 302, no. 1, pp. 26-35, 2002.

[73] S. Bakthavatsalam, S. D. Sharma, M. Sonawane, V. Thirumalai, and A. Datta, "A zebrafish model of manganism reveals reversible and treatable symptoms that are independent of neurotoxicity," Disease Models and Mechanisms, vol. 7, no. 11, pp. 1239-1251, 2014.

[74] J. Wang, H. Lou, C. J. Pedersen, A. D. Smith, and R. G. Perez, "14$3-3 \zeta$ contributes to tyrosine hydroxylase activity in MN9D cells: localization of dopamine regulatory proteins to mitochondria," The Journal of Biological Chemistry, vol. 284, no. 21, pp. 1401114019, 2009.

[75] P. Zhang, A. Hatter, and B. Liu, "Manganese chloride stimulates rat microglia to release hydrogen peroxide," Toxicology Letters, vol. 173, no. 2, pp. 88-100, 2007.

[76] Y. Xing, Z. Li, Y. Chen, J. B. Stock, P. D. Jeffrey, and Y. Shi, "Structural mechanism of demethylation and inactivation of protein phosphatase 2A," Cell, vol. 133, no. 1, pp. 154-163, 2008.

[77] J. Donaldson, F. S. LaBella, and D. Gesser, "Enhanced autoxidation of dopamine as a possible basis of manganese neurotoxicity," Neurotoxicology L, no. 1, pp. 53-64, 1981.

[78] X. Liu, K. A. Sullivan, J. E. Madl, M. Legare, and R. B. Tjalkens, "Manganese-induced neurotoxicity: the role of astroglialderived nitric oxide in striatal interneuron degeneration," Toxicological Sciences, vol. 91, no. 2, pp. 521-531, 2006.

[79] T. R. Guilarte, "Manganese neurotoxicity: new perspectives from behavioral, neuroimaging, and neuropathological studies in humans and non-human primates," Frontiers in Aging Neuroscience, vol. 5, article 23, pp. 1-10, 2013.
[80] S. Matsushima, J. Kuroda, T. Ago et al., "Increased oxidative stress in the nucleus caused by Nox4 mediates oxidation of HDAC4 and cardiac hypertrophy," Circulation Research, vol.112, no. 4, pp. 651-663, 2013.

[81] D. Milatovic and M. Aschner, "Measurement of isoprostanes as markers of oxidative stress in neuronal tissue," Current Protocols in Toxicology, vol. 12, no. 14, pp. 1-12, 2009.

[82] D. Milatovic, S. Zaja-Milatovic, R. C. Gupta, Y. Yu, and M. Aschner, "Oxidative damage and neurodegeneration in manganese-induced neurotoxicity," Toxicology and Applied Pharmacology, vol. 240, no. 2, pp. 219-225, 2009.

[83] B. Liu, H.-M. Gao, J.-Y. Wang, G.-H. Jeohn, C. L. Cooper, and J.-S. Hong, "Role of nitric oxide in inflammation-mediated neurodegeneration," Annals of the New York Academy of Sciences, vol. 962, pp. 318-331, 2002.

[84] M. G. Tansey, M. K. McCoy, and T. C. Frank-Cannon, "Neuroinflammatory mechanisms in Parkinson's disease: potential environmental triggers, pathways, and targets for early therapeutic intervention," Experimental Neurology, vol. 208, no. 1, pp. 1-25, 2007.

[85] J. Cuschieri and R. V. Maier, "Mitogen-activated protein kinase (MAPK)," Critical Care Medicine, vol. 33, no. 12, pp. S417-S419, 2005.

[86] H. R. Rezvani, S. Dedieu, S. North et al., "Hypoxia-inducible factor- $1 \alpha$, a key factor in the keratinocyte response to UVB exposure," Journal of Biological Chemistry, vol. 282, no. 22, pp. 16413-16422, 2007.

[87] Y. Hirata, K. Adachi, and K. Kiuchi, "Phosphorylation and activation of p70 S6 kinase by manganese in PC12 cells," NeuroReport, vol. 9, no. 13, pp. 3037-3040, 1998.

[88] J. A. McCubrey, M. M. LaHair, and R. A. Franklin, "Reactive oxygen species-induced activation of the MAP kinase signaling pathways," Antioxidants and Redox Signaling, vol. 8, no. 9-10, pp. 1775-1789, 2006.

[89] K. M. Erikson, D. C. Dorman, V. Fitsanakis, L. H. Lash, and M. Aschner, "Alterations of oxidative stress biomarkers due to in utero and neonatal exposures of airborne manganese," Biological Trace Element Research, vol. 111, no. 1-3, pp. 199-215, 2006.

[90] V. Exil, L. Ping, Y. Yu et al., "Activation of MAPK and FoxO by Manganese ( $\mathrm{Mn})$ in rat neonatal primary astrocyte cultures," PLoS ONE, vol. 9, no. 5, article e94753, 2014.

[91] Y. Hirata, "Manganese-induced apoptosis in PC12 cells," Neurotoxicology and Teratology, vol. 24, no. 5, pp. 639-653, 2002.

[92] W.-C. Chen and C.-C. Chen, "Signal transduction of arginine vasopressin-induced arachidonic acid release in $\mathrm{H} 9 \mathrm{c} 2$ cardiac myoblasts: role of $\mathrm{Ca}^{2+}$ and the protein kinase C-dependent activation of p 42 mitogen-activated protein kinase," Endocrinology, vol. 140, no. 4, pp. 1639-1648, 1999.

[93] S. C. Frasch, P. M. Henson, J. M. Kailey et al., "Regulation of phospholipid scramblase activity during apoptosis and cell activation by protein kinase C $\delta$," Journal of Biological Chemistry, vol. 275, no. 30, pp. 23065-23073, 2000.

[94] I. Vancurova, V. Miskolci, and D. Davidson, "NF- $\kappa$ B activation in tumor necrosis factor $\alpha$-stimulated neutrophils is mediated by protein kinase $\mathrm{C} \delta$. Correlation to nuclear $\mathrm{I} \kappa \mathrm{B} \alpha$," The Journal of Biological Chemistry, vol. 276, no. 23, pp. 19746-19752, 2001.

[95] H. S. Chun, H. Lee, and J. H. Son, "Manganese induces endoplasmic reticulum (ER) stress and activates multiple caspases in nigral dopaminergic neuronal cells, SN4741," Neuroscience Letters, vol. 316, no. 1, pp. 5-8, 2001. 
[96] M. Sidoryk-Wegrzynowicz and M. Aschner, "Manganese toxicity in the central nervous system: the glutamine/glutamate- $\gamma$ aminobutyric acid cycle," Journal of Internal Medicine, vol. 273, no. 5, pp. 466-477, 2013.

[97] B. Dipasquale, A. M. Marini, and R. J. Youle, "Apoptosis and DNA degradation induced by 1-methyl-4-phenylpyridinium in neurons," Biochemical and Biophysical Research Communications, vol. 181, no. 3, pp. 1442-1448, 1991.

[98] C. Ma, S. N. Schneider, M. Miller et al., "Manganese accumulation in the mouse ear following systemic exposure," Journal of Biochemical and Molecular Toxicology, vol. 22, no. 5, pp. 305310, 2008

[99] J. Salazar, N. Mena, S. Hunot et al., "Divalent metal transporter 1 (DMT1) contributes to neurodegeneration in animal models of Parkinson's disease," Proceedings of the National Academy of Sciences of the United States of America, vol. 105, no. 47, pp. 18578-18583, 2008.

[100] D. Ding, J. Roth, and R. Salvi, "Manganese is toxic to spiral ganglion neurons and hair cells in vitro," NeuroToxicology, vol. 32, no. 2, pp. 233-241, 2011.

[101] B. Li, M. Carey, and J. L. Workman, "The role of chromatin during transcription," Cell, vol. 128, no. 4, pp. 707-719, 2007.

[102] T. Kouzarides, "Chromatin modifications and their function," Cell, vol. 128, no. 4, pp. 693-705, 2007.

[103] R. Martinez-Zamudio and H. C. Ha, "Environmental epigenetics in metal exposure," Epigenetics, vol. 6, no. 7, pp. 820-827, 2011.

[104] B. A. Fowler, M. H. Whittaker, M. Lipsky, G. Wang, and X.-Q. Chen, "Oxidative stress induced by lead, cadmium and arsenic mixtures: 30-day, 90-day, and 180-day drinking water studies in rats: an overview," BioMetals, vol. 17, no. 5, pp. 567-568, 2004.

[105] K. V. Donkena, C. Y. F. Young, and D. J. Tindall, "Oxidative stress and DNA methylation in prostate cancer," Obstetrics and Gynecology International, vol. 2010, Article ID 302051, 14 pages, 2010.

[106] P. W. Turk, A. Laayoun, S. S. Smith, and S. A. Weitzman, "DNA adduct 8-hydroxyl-2/-deoxyguanosine (8-hydroxyguanine) affects function of human DNA methyltransferase," Carcinogenesis, vol. 16, no. 5, pp. 1253-1255, 1995.

[107] M. Valko, C. J. Rhodes, J. Moncol, M. Izakovic, and M. Mazur, "Free radicals, metals and antioxidants in oxidative stressinduced cancer," Chemico-Biological Interactions, vol. 160, no. 1, pp. 1-40, 2006.

[108] X. Nan, H.-H. Ng, C. A. Johnson et al., "Transcriptional repression by the methyl-CpG-binding protein $\mathrm{MeCP} 2$ involves a histone deacetylase complex," Nature, vol. 393, no. 6683, pp. 386-389, 1998.

[109] P. L. Jones, G. J. C. Veenstra, P. A. Wade et al., "Methylated DNA and $\mathrm{MeCP} 2$ recruit histone deacetylase to repress transcription," Nature Genetics, vol. 19, no. 2, pp. 187-191, 1998.

[110] W.-G. Zhu, K. Srinivasan, Z. Dai et al., "Methylation of adjacent CpG sites affects Sp1/Sp3 binding and activity in the $p 21^{C i p 1}$ promoter," Molecular and Cellular Biology, vol. 23, no. 12, pp. 4056-4065, 2003.

[111] V. Valinluck, H.-H. Tsai, D. K. Rogstad, A. Burdzy, A. Bird, and L. C. Sowers, "Oxidative damage to methyl-CpG sequences inhibits the binding of the methyl-CpG binding domain (MBD) of methyl-CpG binding protein 2 (MeCP2)," Nucleic Acids Research, vol. 32, no. 14, pp. 4100-4108, 2004.

[112] X.-M. Shen and G. Dryhurst, "Iron- and manganese-catalyzed autoxidation of dopamine in the presence of L-cysteine: possible insights into iron- and manganese-mediated dopaminergic neurotoxicity," Chemical Research in Toxicology, vol. 11, no. 7, pp. 824-837, 1998.

[113] Y. Niu, T. L. DesMarais, Z. Tong, Y. Yao, and M. Costa, "Oxidative stress alters global histone modification and DNA methylation," Free Radical Biology and Medicine, vol. 82, pp. 2228, 2015.

[114] J. He, M. Wang, Y. Jiang et al., "Chronic arsenic exposure and angiogenesis in human bronchial epithelial cells via the ROS/miR-199a-5p/HIF-1 $\alpha /$ COX-2 pathway," Environmental Health Perspectives, vol. 122, no. 3, pp. 255-261, 2014.

[115] A. Giatromanolaki, M. I. Koukourakis, E. Sivridis et al., "Relation of hypoxia inducible factor $1 \alpha$ and $2 \alpha$ in operable non-small cell lung cancer to angiogenic/molecular profile of tumours and survival," British Journal of Cancer, vol. 85, no. 6, pp. 881-890, 2001.

[116] H.-W. Hwang, L. L. Baxter, S. K. Loftus et al., "Distinct microRNA expression signatures are associated with melanoma subtypes and are regulated by HIF1A," Pigment Cell and Melanoma Research, vol. 27, no. 5, pp. 777-787, 2014.

[117] M. Nakayama, C. J. Bennett, J. L. Hicks et al., "Hypermethylation of the human glutathione $S$-transferase- $\pi$ gene (GSTP1) $\mathrm{CpG}$ island is present in a subset of proliferative inflammatory atrophy lesions but not in normal or hyperplastic epithelium of the prostate: a detailed study using laser-capture microdissection," The American Journal of Pathology, vol. 163, no. 3, pp. 923-933, 2003.

[118] M. Valko, M. Izakovic, M. Mazur, C. J. Rhodes, and J. Telser, "Role of oxygen radicals in DNA damage and cancer incidence," Molecular and Cellular Biochemistry, vol. 266, no. 1-2, pp. 37-56, 2004.

[119] S.-O. Lim, J.-M. Gu, M. S. Kim et al., "Epigenetic changes induced by reactive oxygen species in hepatocellular carcinoma: methylation of the E-cadherin promoter," Gastroenterology, vol. 135, no. 6, pp. 2128-2140, 2008.

[120] M. Chahrour, Y. J. Sung, C. Shaw et al., "MeCP2, a key contributor to neurological disease, activates and represses transcription," Science, vol. 320, no. 5880, pp. 1224-1229, 2008.

[121] W. J. Lukiw and A. I. Pogue, "Induction of specific micro RNA (miRNA) species by ROS-generating metal sulfates in primary human brain cells," Journal of Inorganic Biochemistry, vol. 101, no. 9, pp. 1265-1269, 2007.

[122] S. L. Berger, "The complex language of chromatin regulation during transcription," Nature, vol. 447, no. 7143, pp. 407-412, 2007.

[123] L. Cantone, F. Nordio, L. Hou et al., "Inhalable metal-rich air particles and histone H3K4 dimethylation and H3K9 Acetylation in a Cross-sectional Study of Steel Workers," Environmental Health Perspectives, vol. 119, no. 7, pp. 964-969, 2011.

[124] H. Braak, E. Ghebremedhin, U. Rüb, H. Bratzke, and K. Del Tredici, "Stages in the development of Parkinson's diseaserelated pathology," Cell and Tissue Research, vol. 318, no. 1, pp. 121-134, 2004.

[125] W. Dauer and S. Przedborski, "Parkinson's disease: mechanisms and models," Neuron, vol. 39, no. 6, pp. 889-909, 2003.

[126] K. F. Winklhofer and C. Haass, "Mitochondrial dysfunction in Parkinson's disease," Biochimica et Biophysica Acta, vol. 1802, no. 1, pp. 29-44, 2010.

[127] G. S. Tanner and S. M. Goldman, "Epidemiology of Parkinson's disease," Neurologic Clinics, vol. 14, no. 2, pp. 317-335, 1996.

[128] M. G. Spillantini, M. L. Schmidt, V. M.-Y. Lee, J. Q. Trojanowski, R. Jakes, and M. Goedert, " $\alpha$-Synuclein in lewy bodies," Nature, vol. 388 , no. 6645 , pp. 839-840, 1997. 
[129] M. V. Padmaja, M. Jayaraman, A. V. Srinivasan, C. R. S. Srisailapathy, and A. Ramesh, "PARK2 gene mutations in early onset Parkinson's disease patients of South India," Neuroscience Letters, vol. 523, no. 2, pp. 145-147, 2012.

[130] B. C. L. Lai, S. A. Marion, K. Teschke, and J. K. C. Tsui, "Occupational and environmental risk factors for Parkinson's disease," Parkinsonism and Related Disorders, vol. 8, no. 5, pp. 297-309, 2002.

[131] T. R. Guilarte and K. K. Gonzales, "Manganese-induced parkinsonism is not idiopathic Parkinson's disease: environmental and genetic evidence," Toxicological Sciences, vol. 146, no. 2, pp. $204-$ 212, 2015.

[132] G. Xiromerisiou, E. Dardiotis, V. Tsimourtou et al., "Genetic basis of Parkinson disease," Neurosurgical Focus, vol. 28, no. 1, article E7, 2010.

[133] E.-K. Tan and L. M. Skipper, "Pathogenic mutations in Parkinson disease," Human Mutation, vol. 28, no. 7, pp. 641-653, 2007.

[134] B. I. Giasson and V. M.-Y. Lee, "Are ubiquitination pathways central to Parkinson's disease?" Cell, vol. 114, no. 1, pp. 1-8, 2003.

[135] C. Au, A. Benedetto, and M. Aschner, "Manganese transport in eukaryotes: the role of DMT1," NeuroToxicology, vol. 29, no. 4, pp. 569-576, 2008.

[136] M. Aschner, T. R. Guilarte, J. S. Schneider, and W. Zheng, "Manganese: recent advances in understanding its transport and neurotoxicity," Toxicology and Applied Pharmacology, vol. 221, no. 2, pp. 131-147, 2007.

[137] J. A. Roth, S. Singleton, J. Feng, M. Garrick, and P. N. Paradkar, "Parkin regulates metal transport via proteasomal degradation of the $1 \mathrm{~B}$ isoforms of divalent metal transporter 1," Journal of Neurochemistry, vol. 113, no. 2, pp. 454-464, 2010.

[138] A. D. Gitler, A. Chesi, M. L. Geddie et al., " $\alpha$-Synuclein is part of a diverse and highly conserved interaction network that includes PARK9 and manganese toxicity," Nature Genetics, vol. 41, pp. 308-315, 2009.

[139] R. Kumaran, J. Vandrovcova, C. Luk et al., "Differential DJ-1 gene expression in Parkinson's disease," Neurobiology of Disease, vol. 36, no. 2, pp. 393-400, 2009.

[140] J. Choi, M. C. Sullards, J. A. Olzmann et al., "Oxidative damage of DJ-1 is linked to sporadic Parkinson and Alzheimer diseases," Journal of Biological Chemistry, vol. 281, no. 16, pp. 10816-10824, 2006.

[141] J. C. Greene, A. J. Whitworth, I. Kuo, L. A. Andrews, M. B. Feany, and L. J. Pallanck, "Mitochondrial pathology and apoptotic muscle degeneration in Drosophila parkin mutants," Proceedings of the National Academy of Sciences of the United States of America, vol. 100, no. 7, pp. 4078-4083, 2003.

[142] I. Irrcher, H. Aleyasin, E. L. Seifert et al., "Loss of the Parkinson's disease-linked gene DJ-1 perturbs mitochondrial dynamics," Human Molecular Genetics, vol. 19, no. 19, pp. 3734-3746, 2010.

[143] E. Miñones-Moyano, S. Porta, G. Escaramís et al., "MicroRNA profiling of Parkinson's disease brains identifies early downregulation of $\mathrm{miR}-34 \mathrm{~b} / \mathrm{c}$ which modulate mitochondrial function," Human Molecular Genetics, vol. 20, no. 15, pp. 3067-3078, 2011.

[144] J. J. Palacino, D. Sagi, M. S. Goldberg et al., "Mitochondrial dysfunction and oxidative damage in parkin-deficient mice," The Journal of Biological Chemistry, vol. 279, no. 18, pp. 1861418622, 2004.

[145] Y. Pesah, T. Pham, H. Burgess et al., "Drosophila parkin mutants have decreased mass and cell size and increased sensitivity to oxygen radical stress," Development, vol. 131, no. 9, pp. 21832194, 2004.
[146] L. Petrucelli, C. O’Farrell, P. J. Lockhart et al., "Parkin protects against the toxicity associated with mutant $\alpha$-synuclein: proteasome dysfunction selectively affects catecholaminergic neurons," Neuron, vol. 36, no. 6, pp. 1007-1019, 2002.

[147] A. K. Berger, G. P. Cortese, K. D. Amodeo, A. Weihofen, A. Letai, and M. J. LaVoie, "Parkin selectively alters the intrinsic threshold for mitochondrial cytochrome c release," Human Molecular Genetics, vol. 18, no. 22, pp. 4317-4328, 2009.

[148] D. R. Green and G. Kroemer, "The pathophysiology of mitochondrial cell death," Science, vol. 305, no. 5684, pp. 626-629, 2004.

[149] D. Eliezer, E. Kutluay, R. Bussell Jr., and G. Browne, "Conformational properties of $\alpha$-synuclein in its free and lipid-associated states," Journal of Molecular Biology, vol. 307, no. 4, pp. 10611073, 2001.

[150] S.-I. Kubo, V. M. Nemani, R. J. Chalkley et al., "A combinatorial code for the interaction of $\alpha$-synuclein with membranes," The Journal of Biological Chemistry, vol. 280, no. 36, pp. 3166431672, 2005.

[151] M. R. Cookson, “ $\alpha$-Synuclein and neuronal cell death," Molecular Neurodegeneration, vol. 4, no. 1, article 4, 2009.

[152] A. Recchia, P. Debetto, A. Negro, D. Guidolin, S. D. Skaper, and P. Giusti, " $\alpha$-Synuclein and Parkinson's disease," The FASEB Journal, vol. 18, no. 6, pp. 617-626, 2004.

[153] W. P. Gai, H. X. Yuan, X. Q. Li, J. T. H. Power, P. C. Blumbergs, and $\mathrm{P}$. H. Jensen, "In situ and in vitro study of colocalization and segregation of $\alpha$-synuclein, ubiquitin, and lipids in Lewy bodies," Experimental Neurology, vol. 166, no. 2, pp. 324-333, 2000.

[154] M. Hashimoto, L. J. Hsu, Y. Xia et al., "Oxidative stress induces amyloid-like aggregate formation of $\mathrm{NACP} / \alpha$ - synuclein in vitro," NeuroReport, vol. 10, no. 4, pp. 717-721, 1999.

[155] J. Xu, S.-Y. Kao, F. J. S. Lee, W. Song, L.-W. Jin, and B. A. Yankner, "Dopamine-dependent neurotoxicity of $\alpha$-synuclein: a mechanism for selective neurodegeneration in Parkinson disease," Nature Medicine, vol. 8, no. 6, pp. 600-606, 2002.

[156] J. Gründemann, F. Schlaudraff, O. Haeckel, and B. Liss, "Elevated $\alpha$-synuclein mRNA levels in individual UV-lasermicrodissected dopaminergic substantia nigra neurons in idiopathic Parkinson's disease," Nucleic Acids Research, vol. 36, no. 7, article e38, 2008.

[157] I. Mizuta, W. Satake, Y. Nakabayashi et al., "Multiple candidate gene analysis identifies $\alpha$-synuclein as a susceptibility gene for sporadic Parkinson's disease," Human Molecular Genetics, vol. 15, no. 7, pp. 1151-1158, 2006.

[158] A. Jowaed, I. Schmitt, O. Kaut, and U. Wüllner, "Methylation regulates alpha-synuclein expression and is decreased in Parkinson's disease patients' brains," The Journal of Neuroscience, vol. 30, no. 18, pp. 6355-6359, 2010.

[159] L. Matsumoto, H. Takuma, A. Tamaoka et al., "CpG demethylation enhances alpha-synuclein expression and affects the pathogenesis of Parkinson's disease," PLoS ONE, vol. 5, no. 11, Article ID e15522, 2010.

[160] G. E. Voutsinas, E. F. Stavrou, G. Karousos et al., "Allelic imbalance of expression and epigenetic regulation within the alpha-synuclein wild-type and p.Ala53Thr alleles in Parkinson disease," Human Mutation, vol. 31, no. 6, pp. 685-691, 2010.

[161] D. Bönsch, B. Lenz, J. Kornhuber, and S. Bleich, "DNA hypermethylation of the alpha synuclein promoter in patients with alcoholism," Neuroreport, vol. 16, no. 2, pp. 167-170, 2005. 
[162] H. Frieling, A. Gozner, K. D. Römer et al., "Global DNA hypomethylation and DNA hypermethylation of the alpha synuclein promoter in females with anorexia nervosa," Molecular Psychiatry, vol. 12, no. 3, pp. 229-230, 2007.

[163] E. Junn, K.-W. Lee, S. J. Byeong, T. W. Chan, J.-Y. Im, and M. M. Mouradian, "Repression of $\alpha$-synuclein expression and toxicity by microRNA-7," Proceedings of the National Academy of Sciences of the United States of America, vol. 106, no. 31, pp. 13052-13057, 2009.

[164] S. Vartiainen, P. Pehkonen, M. Lakso, R. Nass, and G. Wong, "Identification of gene expression changes in transgenic $C$. elegans overexpressing human $\alpha$-synuclein," Neurobiology of Disease, vol. 22, no. 3, pp. 477-486, 2006.

[165] E. Doxakis, "Post-transcriptional regulation of $\alpha$-synuclein expression by mir-7 and mir-153," The Journal of Biological Chemistry, vol. 285, no. 17, pp. 12726-12734, 2010.

[166] S. Asikainen, M. Rudgalvyte, L. Heikkinen et al., "Global microRNA expression profiling of caenorhabditis elegans Parkinson's disease models," Journal of Molecular Neuroscience, vol. 41, no. 1, pp. 210-218, 2010.

[167] F. Gillardon, M. Mack, W. Rist et al., "MicroRNA and proteome expression profiling in early-symptomatic $\alpha$-synuclein(A30P)transgenic mice," Proteomics, vol. 2, no. 5, pp. 697-705, 2008.

[168] J. Kim, K. Inoue, J. Ishii et al., "A microRNA feedback circuit in midbrain dopamine neurons," Science, vol. 317, no. 5842, pp. 1220-1224, 2007.

[169] G. Wang, J. M. van der Walt, G. Mayhew et al., "Variation in the miRNA-433 binding site of FGF20 confers risk for Parkinson disease by overexpression of $\alpha$-synuclein," The American Journal of Human Genetics, vol. 82, no. 2, pp. 283-289, 2008.

[170] P. Foulds, D. M. A. Mann, J. D. Mitchell, and D. Allsop, "Parkinson disease: progress towards a molecular biomarker for Parkinson disease," Nature Reviews Neurology, vol. 6, no. 7, pp. 359-361, 2010.

[171] W. J. Schulz-Schaeffer, "The synaptic pathology of $\alpha$-synuclein aggregation in dementia with Lewy bodies, Parkinson's disease and Parkinson's disease dementia," Acta Neuropathologica, vol. 120, no. 2, pp. 131-143, 2010.

[172] R. E. Burke, "Programmed cell death and new discoveries in the genetics of parkinsonism," Journal of Neurochemistry, vol. 104, no. 4, pp. 875-890, 2008.

[173] C. Zhou, Y. Huang, and S. Przedborski, "Oxidative stress in Parkinson's disease: a mechanism of pathogenic and therapeutic significance," Annals of the New York Academy of Sciences, vol. 1147, pp. 93-104, 2008.

[174] J. P. Covy and B. I. Giasson, " $\alpha$-Synuclein, leucine-rich repeat kinase-2, and manganese in the pathogenesis of parkinson disease," NeuroToxicology, vol. 32, no. 5, pp. 622-629, 2011.

[175] R. Cappai, S.-L. Leek, D. J. Tew et al., "Dopamine promotes $\alpha$ synuclein aggregation into SDS-resistant soluble oligomers via a distinct folding pathway," FASEB Journal, vol. 19, no. 10, pp. 1377-1379, 2005.

[176] M. Lakso, S. Vartiainen, A.-M. Moilanen et al., "Dopaminergic neuronal loss and motor deficits in Caenorhabditis elegans overexpressing human $\alpha$-synuclein," Journal of Neurochemistry, vol. 86, no. 1, pp. 165-172, 2003.

[177] M. J. Volles and P. T. Lansbury Jr., "Zeroing in on the pathogenic form of $\alpha$-Synuclein and its mechanism of neurotoxicity in Parkinson's disease," Biochemistry, vol. 42, no. 26, pp. 7871-7878, 2003.
[178] J.-H. Seo, J.-C. Rah, S. H. Choi et al., "Alpha-synuclein regulates neuronal survival via $\mathrm{Bcl}-2$ family expression and PI3/Akt kinase pathway," The FASEB Journal, vol. 16, no. 13, pp. 18261828, 2002.

[179] J. Goers, A. B. Manning-Bog, A. L. McCormack et al., "Nuclear localization of $\alpha$-synuclein and its interaction with histones," Biochemistry, vol. 42, no. 28, pp. 8465-8471, 2003.

[180] S. Xu, M. Zhou, S. Yu et al., "Oxidative stress induces nuclear translocation of C-terminus of $\alpha$-synuclein in dopaminergic cells," Biochemical and Biophysical Research Communications, vol. 342, no. 1, pp. 330-335, 2006.

[181] H. Jin, A. Kanthasamy, A. Ghosh, Y. Yang, V. Anantharam, and A. G. Kanthasamy, " $\alpha$-Synuclein negatively regulates protein kinase $\mathrm{C} \delta$ expression to suppress apoptosis in dopaminergic neurons by reducing p300 histone acetyltransferase activity," The Journal of Neuroscience, vol. 31, no. 6, pp. 2035-2051, 2011.

[182] P. J. Jensen, B. J. Alter, and K. L. O’Malley, “ $\alpha$-synuclein protects naive but not dbcAMP-treated dopaminergic cell types from 1-methyl-4-phenylpyridinium toxicity," Journal of Neurochemistry, vol. 86, no. 1, pp. 196-209, 2003.

[183] E. Kontopoulos, J. D. Parvin, and M. B. Feany, “ $\alpha$-Synuclein acts in the nucleus to inhibit histone acetylation and promote neurotoxicity," Human Molecular Genetics, vol. 15, no. 20, pp. 3012-3023, 2006.

[184] V. Anantharam, M. Kitazawa, J. Wagner, S. Kaul, and A. G. Kanthasamy, "Caspase-3-dependent proteolytic cleavage of protein kinase Cdelta is essential for oxidative stress-mediated dopaminergic cell death after exposure to methylcyclopentadienyl manganese tricarbonyl," Journal of Neuroscience, vol. 22, no. 5, pp. 1738-1751, 2012.

[185] S. Kaul, A. Kanthasamy, M. Kitazawa, V. Anantharam, and A. G. Kanthasamy, "Caspase-3 dependent proteolytic activation of protein kinase $\mathrm{C} \delta$ mediates and regulates 1-methyl4-phenylpyridinium (MPP+)-induced apoptotic cell death in dopaminergic cells: relevance to oxidative stress in dopaminergic degeneration," European Journal of Neuroscience, vol. 18, no. 6, pp. 1387-1401, 2003.

[186] A. G. Kanthasamy, M. Kitazawa, A. Kanthasamy, and V. Anantharam, "Role of proteolytic activation of protein kinase $\mathrm{C} \delta$ in oxidative stress-induced apoptosis," Antioxidants and Redox Signaling, vol. 5, no. 5, pp. 609-620, 2003.

[187] S. K. Kidd and J. S. Schneider, "Protection of dopaminergic cells from $\mathrm{MPP}^{+}$-mediated toxicity by histone deacetylase inhibition," Brain Research, vol. 1354, pp. 172-178, 2010.

[188] T. F. Outeiro, E. Kontopoulos, S. M. Altmann et al., "Sirtuin 2 inhibitors rescue $\alpha$-synuclein-mediated toxicity in models of Parkinson's disease," Science, vol. 317, no. 5837, pp. 516-519, 2007.

[189] N. Ostrerova, L. Petrucelli, M. Farrer et al., " $\alpha$-Synuclein shares physical and functional homology with 14-3-3 proteins," Journal of Neuroscience, vol. 19, no. 14, pp. 5782-5791, 1999.

[190] P. Desplats, B. Spencer, E. Coffee et al., " $\alpha$-synuclein sequesters Dnmtl from the nucleus: a novel mechanism for epigenetic alterations in Lewy body diseases," Journal of Biological Chemistry, vol. 286, no. 11, pp. 9031-9037, 2011.

[191] M. Covic, E. Karaca, and D. C. Lie, "Epigenetic regulation of neurogenesis in the adult hippocampus," Heredity, vol. 105, no. 1, pp. 122-134, 2010.

[192] J. Sun, J. Sun, G.-L. Ming, and H. Song, "Epigenetic regulation of neurogenesis in the adult mammalian brain," European Journal of Neuroscience, vol. 33, no. 6, pp. 1087-1093, 2011. 
[193] L. Wang, T. Ohishi, A. Shiraki et al., "Developmental exposure to manganese chloride induces sustained aberration of neurogenesis in the hippocampal dentate gyrus of mice," Toxicological Sciences, vol. 127, no. 2, pp. 508-521, 2012.

[194] L. Wang, A. Shiraki, M. Itahashi et al., "Aberration in epigenetic gene regulation in hippocampal neurogenesis by developmental exposure to manganese chloride in mice," Toxicological Sciences, vol. 136, no. 1, pp. 154-165, 2013.

[195] K. R. Saradalekshmi, N. V. Neetha, S. Sathyan, I. V. Nair, C. M. Nair, and M. Banerjee, "DNA methyl transferase (DNMT) gene polymorphisms could be a primary event in epigenetic susceptibility to schizophrenia," PLoS ONE, vol. 9, no. 5, article e98182, 2014.

[196] E. A. Kim, H.-K. Cheong, K.-D. Joo et al., "Effect of manganese exposure on the neuroendocrine system in welders," NeuroToxicology, vol. 28, no. 2, pp. 263-269, 2007.

[197] Y. X. Zheng, P. Chan, Z. F. Pan et al., "Polymorphism of metabolic genes and susceptibility to occupational chronic manganism," Biomarkers, vol. 7, no. 4, pp. 337-346, 2002.

[198] N. Vinayagamoorthy, K. Krishnamurthi, S. S. Devi et al., "Genetic polymorphism of CYP2D6*2 C $\rightarrow$ T 2850, GSTM1, NQO1 genes and their correlation with biomarkers in manganese miners of Central India," Chemosphere, vol. 81, no. 10, pp. 1286-1291, 2010.

[199] I. Mena, K. Horiuchi, K. Burke, and G. C. Cotzias, "Chronic manganese poisoning: individual susceptibility and absorption of iron," Neurology, vol. 19, no. 10, pp. 1000-1006, 1969.

[200] E. H. Hanson, G. Imperatore, and W. Burke, "HFE gene and hereditary hemochromatosis: a HuGE review. Human Genome Epidemiology," American Journal of Epidemiology, vol. 154, no. 3, pp. 193-206, 2001.

[201] J. N. Feder, D. M. Penny, A. Irrinki et al., "The hemochromatosis gene product complexes with the transferrin receptor and lowers its affinity for ligand binding," Proceedings of the National Academy of Sciences of the United States of America, vol. 95, no. 4, pp. 1472-1477, 1998.

[202] B. Claus Henn, J. Kim, M. Wessling-Resnick et al., "Associations of iron metabolism genes with blood manganese levels: a population-based study with validation data from animal models," Environmental Health: A Global Access Science Source, vol. 10, article $97,2011$. 

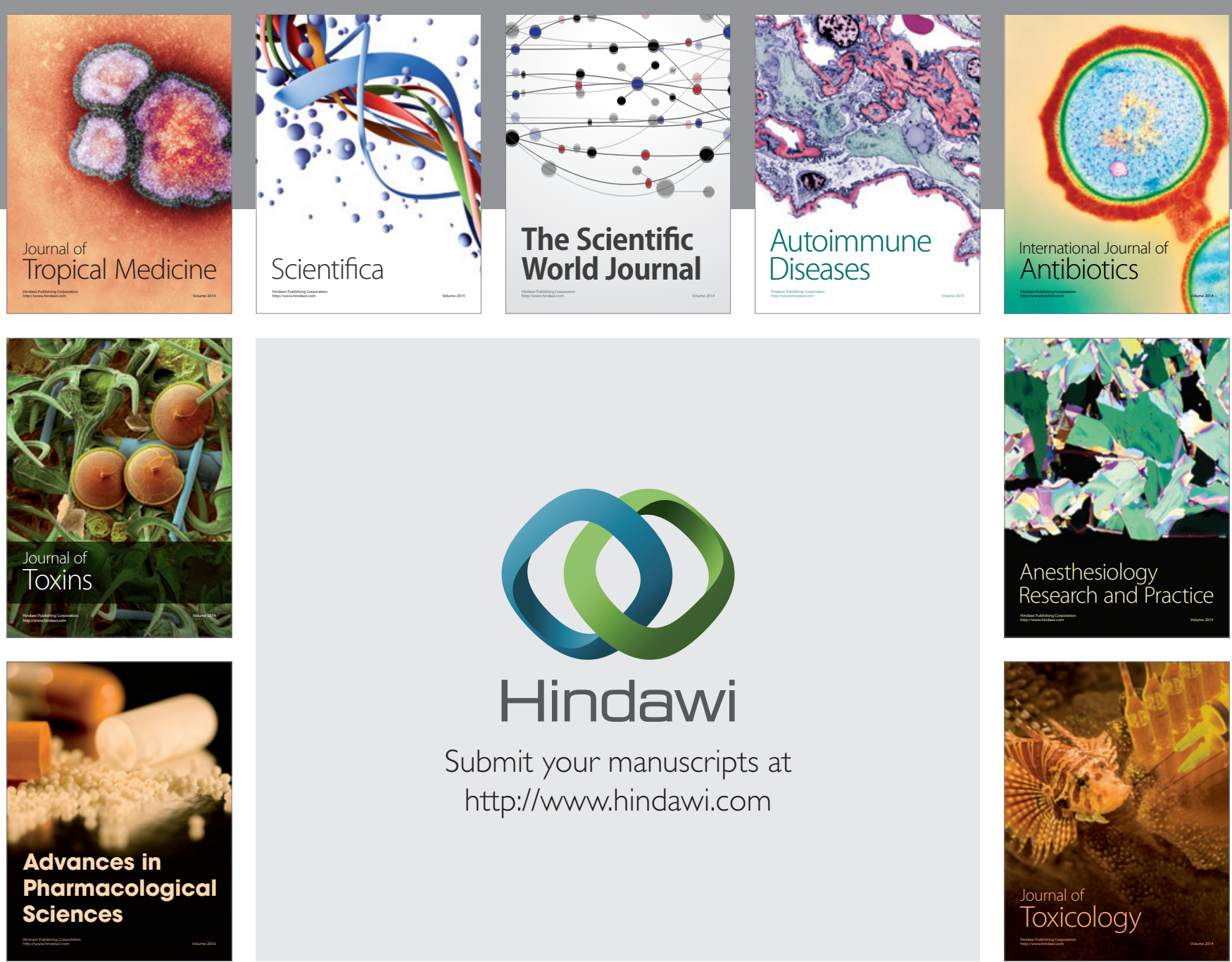

\section{Hindawi}

Submit your manuscripts at

http://www.hindawi.com
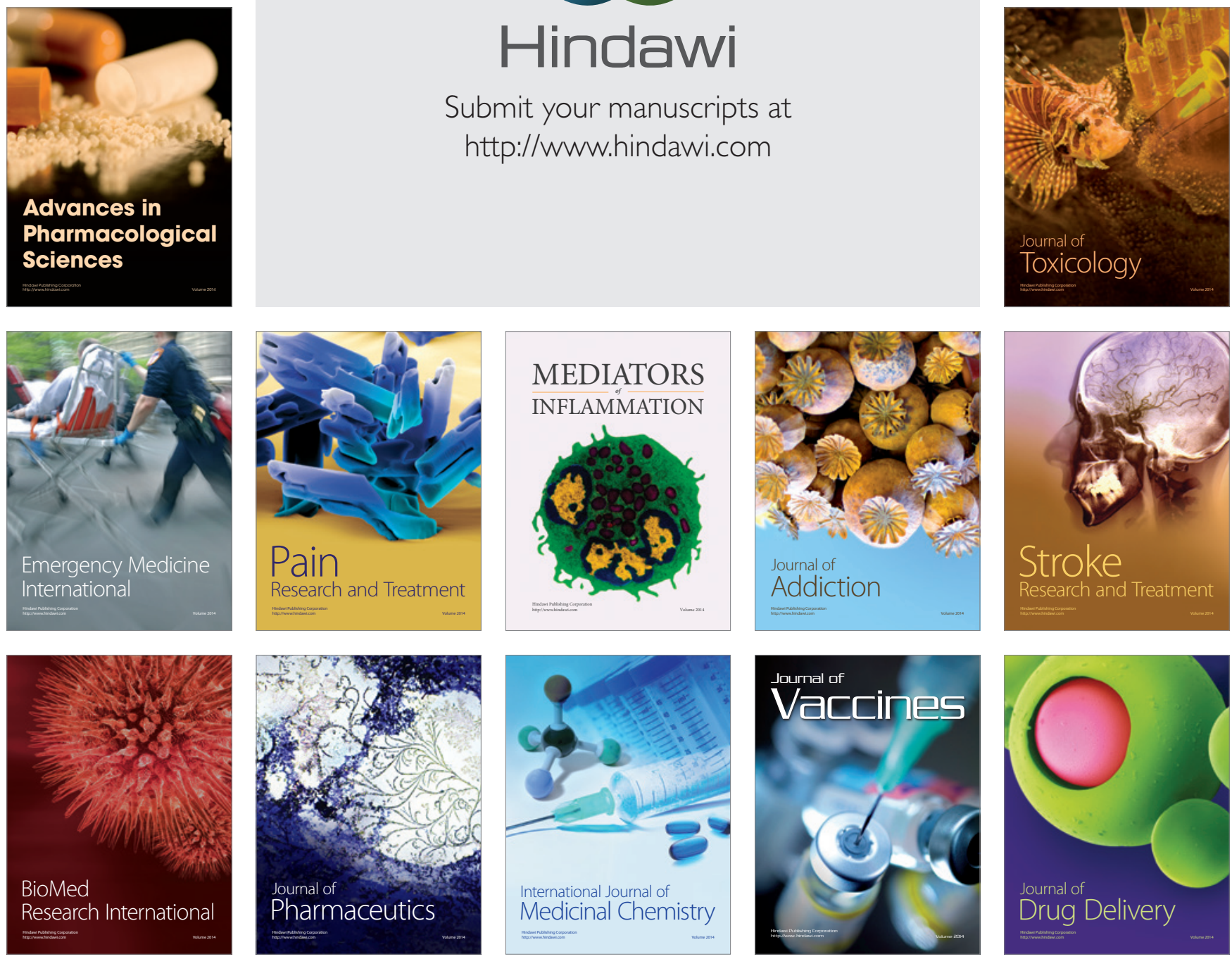